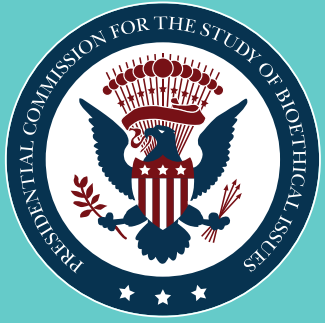

ETHICS and EBOLA

Public Health Planning and Response

Presidential Commission for the Study of Bioethical Issues

February 2015 
On the cover: Created by Centers for Disease Control and Prevention (CDC) microbiologist Frederick A. Murphy, this transmission electron micrograph (TEM) revealed some of the ultrastructural morphology displayed by an Ebola virus virion. (Image colorization applied.) Credit: Frederick A. Murphy, 1976

Source: CDC Public Health Image Library 


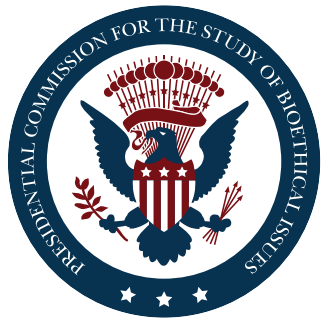

ETHICS and EBOLA

Public Health Planning and Response

Presidential Commission for the Study of Bioethical Issues

Washington, D.C.

February 2015

http://www.bioethics.gov 


\section{ABOUT THE PRESIDENTIAL COMMISSION FOR \\ THE STUDY OF BIOETHICAL ISSUES}

The Presidential Commission for the Study of Bioethical Issues (Bioethics Commission) is an advisory panel of the nation's leaders in medicine, science, ethics, religion, law, and engineering. The Bioethics Commission advises the President on bioethical issues arising from advances in biomedicine and related areas of science and technology. The Bioethics Commission seeks to identify and promote policies and practices that ensure scientific research, health care delivery, and technological innovation are conducted in a socially and ethically responsible manner.

For more information about the Bioethics Commission, please see http://www. bioethics.gov.

The use of trade names and commercial sources in this report is for identification only and does not imply endorsement. 


\section{CONTENTS}

Letter of Transmittal to the President .................................................................................. iv

Members of the Bioethics Commission ...............................................................................vi

Bioethics Commission Staff and Consultants.................................................................vii

Acknowledgements........................................................................................................... viii

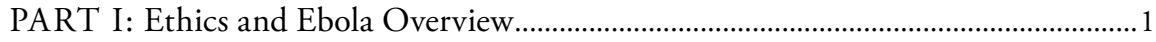

Ethical and Prudential Justifications for U.S. Engagement in Global Health Emergencies

Liberty-Restricting Public Health Interventions and the Principle of

Least Infringement .7

Proactive Democratic Deliberation and Education .............................................. 8

The Current Ebola Epidemic.................................................................................

Ebola in the United States ..................................................................................... 13

Analysis and Recommendations ............................................................................. 16

PART II: Health Planning and Response in Context..................................................21

Quarantine and Other Restrictive Measures During Public Health Emergencies.... 22

Overview of Restrictive Public Health Measures................................................22

Ethical Considerations Regarding Quarantine and Other Restrictive Measures ....24

Lessons Learned: Past and Present Public Health Use of Restrictive Measures....26

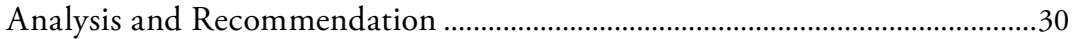

Research Ethics During Public Health Emergencies .................................................32

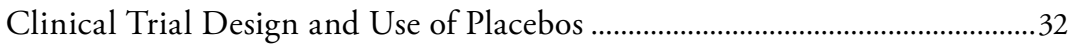

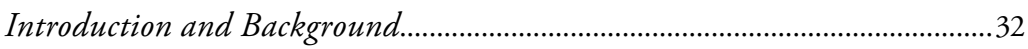

The Argument for Placebo-Controlled Clinical Trials during the

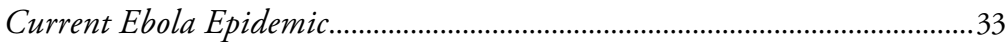

The Argument against Placebo-Controlled Clinical Trials during the

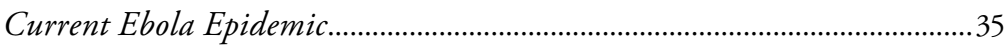

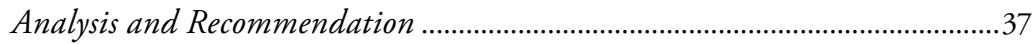

Collection, Use, and International Sharing of Biospecimens for Research ...43

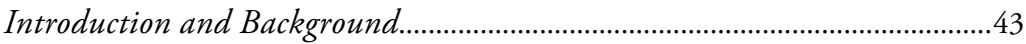

Ethical and Practical Challenges.....................................................................4

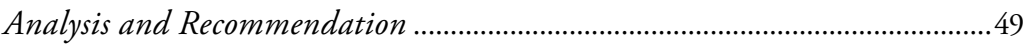

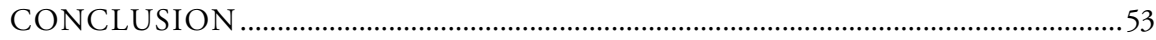

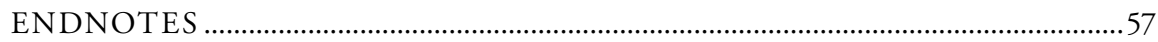

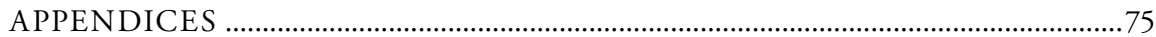

Appendix I: Map of Countries Most Affected by 2014-2015 Ebola Epidemic....76

Appendix II: Guest Presenters to the Bioethics Commission Regarding Ethics,

Public Health Emergency Preparedness and Response, and the Ebola Epidemic....77 


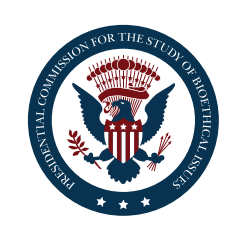

Presidential Commission for the Study of Bioethical Issues

President Barack Obama

The White House

1600 Pennsylvania Avenue, NW

Washington, DC 20500

Dear Mr. President:

On behalf of the Presidential Commission for the Study of Bioethical Issues, we present to you our brief, Ethics and Ebola: Public Health Planning and Response. In this brief the Bioethics Commission focuses on ethical challenges raised by the current Ebola epidemic in western Africa, with a particular focus on the U.S. response to the epidemic. We address the pressing need to improve key elements of our planning and response capabilities for future public health emergencies, including leadership, transparency, and explicit ethics integration at all levels of public health decision making.

Recognizing the importance of transparent public dialogue and deliberation on public health emergency response and the Ebola epidemic, the Bioethics Commission held two public meetings on this topic, and heard from speakers with diverse backgrounds and perspectives, including medicine, public health, and clinical research; U.S. and African health care professionals; community leaders from the western African diaspora in the United States; and individuals involved in the Ebola response. In addition, the Bioethics Commission solicited public comment and received many thoughtful replies.

The current Ebola epidemic reveals how the response to outbreaks of infectious disease can reflect national values. Deliberate development of public health policies in accordance with high ethical and evidentiary standards is the mark of a society committed to national and global health. U.S. participation in a coordinated global response to this epidemic is both ethically and prudentially required to fulfill our humanitarian obligations as global citizens and to protect our national health security. 
The Bioethics Commission believes that empowered leadership, strong global public health infrastructure, effective communication, and agile ethics expertise are critical to ensuring our capability to respond to the next public health crisis. The best time to reflect comprehensively and deliberate on our readiness is during response planning, not in the midst of an emergency. We must take this opportunity, when the world is focused on global public health, to integrate each of these elements into our existing public health infrastructure.

Here the Bioethics Commission offers seven recommendations to improve domestic and global public health response capabilities and to ensure that specific aspects of emergency response, including the use of restrictive measures such as quarantine, and research conducted during an emergency, are guided by the highest ethical standards and robust public deliberation.

The Bioethics Commission is honored by the trust you have placed in us, and we are grateful for the opportunity to serve you and the nation in this way.

Sincerely,

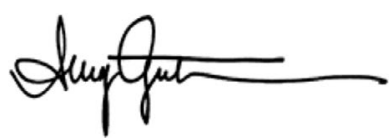

Amy Gutmann, Ph.D.

Chair

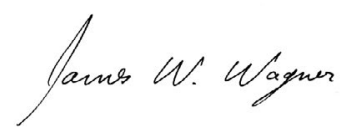

James W. Wagner, Ph.D. Vice Chair 
PRESIDENTIAL COMMISSION FOR THE STUDY OF BIOETHICAL ISSUES

\author{
AMY GUTMANN, Ph.D., CHAIR \\ President and Christopher H. Browne \\ Distinguished Professor of Political Science and Professor of Communication, \\ University of Pennsylvania
}

JAMES W. WAGNER, Ph.D., VICE CHAIR

President, Emory University

ANitA L. Allen, J.D., Ph.D.

Vice Provost for Faculty,

Henry R. Silverman Professor of Law and Professor of Philosophy,

University of Pennsylvania

JOHN D. ARRAS, Ph.D.

Porterfield Professor of Biomedical

Ethics, Professor of Philosophy,

Professor of Public Health Sciences,

University of Virginia

BARBARA F. ATKINSON, M.D.

Planning Dean,

University of Nevada, Las Vegas

School of Medicine

NITA A. FARAHANY, J.D., Ph.D.

Director, Duke Science and Society;

Director, Duke M.A. in Bioethics and

Science Policy; Professor of Law and

Philosophy, Duke University

CHRISTINE GRADY, R.N., Ph.D.

Chief, Department of Bioethics,

National Institutes of Health

Clinical Center
STEPHEN L. HAUSER, M.D.

Robert A. Fishman Distinguished Professor and Chair of the Department of Neurology, University of California, San Francisco

RAJU S. KUCHERLAPATI, Ph.D. Paul C. Cabot Professor, Department of Genetics, Harvard Medical School; Professor, Department of Medicine, Brigham and Women's Hospital

NELSON L. MICHAEL, M.D., Ph.D. Colonel, Medical Corps, U.S. Army; Director, U.S. Military HIV Research Program, Walter Reed Army Institute of Research

DANIEL P. SULMASY, M.D., Ph.D., FACP Kilbride-Clinton Professor of Medicine and Ethics, Department of Medicine and Divinity School; Associate Director, The MacLean Center for Clinical Medical Ethics, University of Chicago 


\section{STAFF AND CONSULTANTS}

\section{Executive Director}

Lisa M. Lee, Ph.D., M.A., M.S.

\section{Associate Directors}

Michelle Groman, J.D.

Kayte Spector-Bagdady, J.D., M. Bioethics

\section{Communications Director}

Hillary Wicai Viers, M.S.J.

\section{Senior Advisors}

Paul A. Lombardo, Ph.D., J.D.

Jonathan D. Moreno, Ph.D.

\section{Research Staff}

Misti Ault Anderson, M.S., M.A.

Kata Chillag, Ph.D.

Elizabeth M. Fenton, Ph.D., M.P.H.

Karen M. Meagher, Ph.D.

Cristina Nigro, M.S.

Elizabeth R. Pike, J.D., LL.M.

Maneesha Sakhuja, M.H.S.

Nicolle K. Strand, J.D., M. Bioethics

Victoria Wilbur, B.A.

Tenny R. Zhang, B.A.

\section{Consultants}

Burness Communications

C. Kay Smith, M.Ed.

Medical Arts Branch, Office of Research

Services, National Institutes of Health

\section{Communications Staff}

Alannah Kittle, M.P.H.

\section{Administrative Staff}

Tynetta Dreher

Esther E. Yoo

\section{Interns}

Minjung Koo, B.A. 


\section{ACKNOWLEDGEMENTS}

The Bioethics Commission is grateful to all those who contributed their time, insight, and energy to this brief. We would like to give special thanks to our diverse group of exceptional speakers for sharing their personal and professional experiences with us and for their continuing commitment to global health and wellbeing. Their wise reflections on these challenging issues contributed to stimulating, thoughtful, and productive discussions at public meetings, and were the foundation of this brief.

The Bioethics Commission is also grateful to its talented staff for their dedicated support, careful research, and thoughtful insights on the ethics of public health emergency preparedness and management, and the particular ethical challenges arising from the ongoing Ebola epidemic in western Africa. We extend our special thanks to Executive Director Lisa M. Lee for her astute leadership on this brief and on all of the Bioethics Commission's work, and to Senior Advisors Paul Lombardo and Jonathan D. Moreno for their perceptive and valuable contributions. The Bioethics Commission is also especially grateful to Associate Director Kayte Spector-Bagdady and lead staff Kata Chillag and Elizabeth Fenton for their responsive and diligent efforts in support of its deliberative process and engagement with this challenging topic. 


\section{PART I \\ Ethics and Ebola Overview}


$\mathbf{B}$ riefly during fall 2014, many U.S. citizens feared that the United States 3 would join affected countries in western Africa in confronting a serious domestic outbreak of the deadly Ebola virus disease (see Appendix I: Map of Countries Most Affected by 2014-2015 Ebola Epidemic). ${ }^{1}$ In response to the arrival of Ebola on U.S. shores, federal and state public health attention and intervention increased. Some responses in the United States-such as calls for travel bans, quarantine of health care workers, and stigmatization of and discrimination against western Africans (or anyone thought to be associated with Ebola) - merit scrutiny, both in relation to this ongoing epidemic and to prepare for future public health emergencies.

As this brief goes to press, there are signs suggesting that the worst Ebola epidemic since the virus's discovery might be starting to abate, particularly in some areas. ${ }^{2}$ There are positive indications of progress and reasons for cautious optimism. The number of new cases appears to be stabilizing or declining in the three hardest hit countries. ${ }^{3}$ In Guinea, schools reopened in January 2015, 5 months after they closed because of the Ebola outbreak. ${ }^{4}$ Many Liberian schools reopened in February 2015, following a 6-month closure. ${ }^{5}$ Still, as public health professionals know, the hardest work of stemming an epidemic is at its end. ${ }^{6}$ This epidemic, like all of those before it, presents the risk of resurgence until there are no transmissions from the last case. Vigilance is required.

Public health professionals, clinicians, and public officials from western Africa and across the world have played no small part in turning the tide of the epidemic. As the Presidential Commission for the Study of Bioethical Issues (Bioethics Commission) makes targeted recommendations for the future, it is committed to recognizing, respecting, and in many cases admiring the hard, good work that was done-and continues to be done-by scores of dedicated health professionals and public officials throughout this Ebola crisis. The analysis and recommendations contained in this brief build on the Bioethics Commission's appreciation and respect for all involved who made things better for those caught in a major public health crisis. The mission here is to recommend what more we can do equitably and effectively to protect health and wellbeing before we are faced with the next Ebola epidemic or other public health emergency_-and while we are still in the midst of the current one. 
As an advisory body to the President of the United States, the Bioethics Commission considers ethical issues with a particular focus on U.S. perspectives and policies, which include U.S. global engagement and its implications in relation to health, science, and technology. As part of its own efforts to contribute to the global Ebola response, the Bioethics Commission has turned its attention to U.S. engagement, focusing on what lessons might be drawn from experiences at home and abroad and making recommendations that support policies and practices that enable a proactive response to epidemics. Specifically, the Bioethics Commission considers what lessons the U.S. involvement in the epidemic has for ethics preparedness for future public health emergencies, emphasizing the role of proactive democratic deliberation in developing responses that reflect public values in a pluralistic society and an increasingly interconnected world.

In Part I of this brief, Ethics and Ebola: Public Health Planning and Response, the Bioethics Commission provides an overview of the ethical challenges related to the current Ebola epidemic and endorses ongoing participation of the United States in the global response for both ethical and prudential reasons. For the United States to engage most effectively in this and other coordinated public health emergency efforts, the Bioethics Commission delineates critical measures for strengthening our domestic and global public health emergency capabilities, with specific recommendations focusing on the importance of accurate, transparent communication and ethics integration throughout the planning and response lifecycle. Part II of this brief applies this principled reasoning in context and analyzes two areas that have become particularly controversial: (1) the ethical use of liberty-restricting public health measures, such as quarantine or travel restrictions to control the epidemic; and (2) research ethics during public health emergencies, focusing on the ethical design of interventional randomized clinical trials as well as the collection, use, and international sharing of biospecimens and related data.

The current Ebola epidemic reveals how our engagement in outbreaks of infectious disease can reflect national values. Deliberate development of public health policies in accordance with high ethical and evidentiary standards is the mark of a society committed to national and global health. Public health emergencies prompt scientific and practical questions about the best methods of prevention and urgent response, but they also raise ethical questions about how to ground such responses in the highest ethical standards. 


\section{ETHICAL AND PRUDENTIAL JUSTIFICATIONS FOR U.S. ENGAGEMENT IN GLOBAL HEALTH EMERGENCIES}

Infectious disease epidemics, and many other public health emergencies, are a matter of U.S. and global concern for both ethical and prudential reasons. We cannot and must not let these considerations be overwhelmed by either fear or complacency. Considering the ethical reasons for U.S. engagement requires reflection on our role in the global community. As is the case with the current Ebola epidemic, many public health emergencies occur or have the most devastating impact in countries and communities least equipped to manage and control them. For example, epidemics often arise in contexts characterized by extreme imbalances in wealth and power, which are often accompanied by health disparities. ${ }^{7}$ Economic and political challenges, although they have many sources, can be perpetuated by unjust global policies that make building and sustaining health infrastructure difficult.

Ethical reasons for engagement in and response to public health emergencies are both humanitarian and justice-based. On humanitarian grounds, the magnitude of suffering and loss of life in the Ebola epidemic support a moral imperative for providing assistance grounded in common humanity-as do many other global public health problems, such as neglected tropical diseases. ${ }^{8}$ Both health professionals and members of the public feel the pull of moral obligations to respond with assistance in the face of profound human suffering. ${ }^{9}$ Such commitments are sometimes articulated in terms of what we owe to each other as members of a global community. ${ }^{10}$
"I think anyone who focuses on Ebola as a case study has to begin by acknowledging the sacred duties that all of us have in shared humanity, but particularly high income countries, to devote ourselves to alleviating suffering in another part of the world. This is particularly, of course, important with an epidemic because it's... in our shared humanity, but it's more than that. It is also in our self-interest because truly the only way that we can avoid risk in our society, in a modern globalized world, is to reduce the reservoir of infection in west Africa. And I think that has to be the very, very first thing that the Commission or anyone else says about this, because that is ethics principle number one."

Gostin, L.O., Founding Linda D. \& Timothy J. O'Neill Professor of Global Health Law; Faculty Director, O'Neill Institute for National \& Global Health Law; Director, World Health Organization Collaborating Center on Public Health Law \& Human Rights; University Professor, Georgetown Law. (2014). Deliberation and Bioethics Education: Case Study of Public Health Emergency Response. Presentation to the Bioethics Commission, November 6. Retrieved February 12, 2015 from http:// bioethics.gov/node/4323. 
On social and global justice grounds, acute health crises like the current Ebola epidemic ethically demand a robust global response. Social justice is a central ethical foundation of public health, entailing a commitment to sufficient levels of health and other dimensions of wellbeing and emphasizing the moral urgency of the health needs of the disadvantaged. ${ }^{11}$ Social justice is also pertinent when implementing response measures, which can disproportionately affect some groups, exacerbating existing inequities. ${ }^{12}$ Further, both health crises and the global responses to them often are shaped by international relationships, including historical control of regions by former colonial powers; for example, current international aid response has largely broken down along the lines of former colonial relationships. ${ }^{13}$ Special obligations to respond to global health crises might arise out of unjust social or economic arrangements that contribute to the conditions under which epidemics occur. ${ }^{14}$ Theories of global justice support obligations of addressing inequalities and poverty, which are often considered more stringent than notions of humanitarianism or charity, and might be demanded in part as redress for past or current injustices. ${ }^{15}$

"All through medical training, you keep hearing the words 'do no harm...,' [but] you kill far more people, cause far more damage by the things you don't do, by the science that you don't apply, the science you don't share, the vaccines you don't use, the inequities that you don't pursue. I think that the single biggest biomedical ethical battleground of today is found in budgets. Budget people do not see themselves as ethicists. Ethicists don't like to spend time on budgets..., [but] why do they continue to reduce funds for public health and prevention?...The reason is because none of us as individuals, as a country, as a globe, actually take health seriously until we lose it. And then we're always behind the curve."

Foege, W., Senior Fellow, Health Policy, Carter Center; Senior Fellow, Global Health Program, Gates Foundation; Emeritus Presidential Distinguished Professor of International Health, Emory University. (2015). Public Health Perspectives on the Current Ebola Epidemic in Western Africa. Presentation to the Bioethics Commission, February 5. Retrieved February 18, 2015 from http://bioethics.gov/node/4591.

Beyond ethical justifications, the second rationale for U.S. engagement in global health emergencies, including the current epidemic, is prudentially based, that is, serving individual or collective interests. Given the capacity of infectious diseases to travel easily in an interconnected world and to destabilize regions or countries, epidemics must be addressed at their source. As public health experts have repeatedly emphasized, the only sure way to prevent Ebola or similar infectious diseases from travelling to previously unaffected places is to stem the disease in highly affected areas-in this case, western 
Africa ${ }^{16}$ Border controls, travel bans, and movement restrictions are of limited effectiveness in containing public health emergencies like the Ebola epidemic. ${ }^{17}$ Responding to outbreaks at their epicenter can be conceptualized in terms of enlightened self-interest, involving an expanded view of what counts as being in one's own interests, given that individual or national interests are tied to the interests of others. ${ }^{18}$ Self-interest grounds a pragmatic rationale for providing assistance for global health emergencies. The shift to connect the public's health to concerns regarding health security can reflect an enlightened selfinterest approach. ${ }^{19}$ Enlightened self-interest also can entail a shift in worldview that comes with the recognition that relationships with others will inevitably require mutuality and reciprocity.

Ethical and prudential rationales for U.S. involvement in response to a global public health emergency can converge in support of engagement or a particular form of engagement. Such rationales can support complementary public health responses that further both health security and humanitarian goals.

\section{PUBLIC PERCEPTIONS OF U.S. GLOBAL HEALTH SPENDING}

In 2013, the Kaiser Family Foundation conducted a nationally representative telephone survey of adult U.S. residents about the U.S. role in global health. When asked, "Just your best guess, what percentage of the federal budget is spent on foreign aid?" on average, Americans answer that 28 percent of the federal budget is spent on foreign aid. When asked, "Do you think the U.S. is now spending too much, too little, or about the right amount on foreign aid?" 61 percent responded "too much," 18 percent "about the right amount," 13 percent "too little," and 7 percent did not know or refused to answer.

In 2012, the United States provided $\$ 8.9$ billion in global health funding, which represents approximately 0.24 percent of the U.S. annual budget. Overall, less than 1 percent of the U.S. annual budget is spent on foreign aid. When survey respondents were told that only about 1 percent of the federal budget is spent on foreign aid, the percentage of respondents answering "too little" doubled, whereas the share responding "too much" halved. ${ }^{20}$ 


\section{Liberty-Restricting Public Health Interventions and the Principle of Least Infringement}

In the context of a public health emergency, the nature of the response also has ethical and prudential dimensions. For both ethical and prudential reasons, public health policies and practices during a public health emergency should be guided by the principle of least infringement, which holds that the least restrictive measures possible should be taken to protect the public's health and health care workers. Any restrictive measures should be grounded in the best available scientific evidence and restrict individual and community liberties only so much as is necessary to protect public health. These measures should not present unnecessary barriers to movement of health care workers to and from affected areas so that they can contribute their skills to the management of the public health emergency and other health problems. ${ }^{21}$ With the presentation of several Ebola cases in the United States during fall 2014, some reactions to the perceived threat of those cases and of the potential for more were not scientifically grounded-as evidenced, for example, by some proposed and enacted state quarantine policies that were ineffective and overly restrictive. In western Africa, some public health interventions, such as the cordon sanitaire (referring to the cordoning off of a geographic area associated with a communicable disease, sometimes known as "gunpoint quarantine") imposed on the impoverished community of West Point in Monrovia, Liberia, have been troubling for their extremity and apparent disregard for basic needs and fundamental freedoms of both individuals and communities. ${ }^{22}$

The principle of least infringement is ethically justified because it respects and protects individual and community needs, interests, rights, and liberties. It is prudentially justified because it gives those most critical to fighting the disease at its source-health care workers and other emergency personnel-the support they need to work safely and effectively.

"I think if you are going to be talking about ethical issues...or common sense issues about quarantine, you have to ask yourself are you quarantining a group of individuals? In this case, all health care workers and all people who come from a region? Are you doing it based on scientific evidence or are you doing it to alleviate public fear? And my conclusion has been that a blanket quarantine for all health care workers, as well as people coming from [western Africa], is much more based on alleviating public fear than it is on scientific data."

Fauci, A.S., Director, National Institute of Allergy and Infectious Diseases, National Institutes of Health (NIH). (2014). Deliberation and Bioethics Education: Case Study of Public Health Emergency Response. Presentation to the Bioethics Commission, November 6. Retrieved February 12, 2015 from http://bioethics.gov/node/4324. 


\section{Proactive Democratic Deliberation and Education}

A range of different and sometimes conflicting values can complicate policy making in a pluralistic society and therefore several approaches to community engagement should be considered, depending on whether we are in the midst of a public health emergency or planning for the next one. A process of democratic deliberation, which includes providing justifications for actions grounded in mutually acceptable reasons for pursuing specific courses of action, facilitates policy making that can incorporate multiple justifications for engagement. Public health rationales premised solely on prudential health security grounds might fail to address human suffering that cannot be directly connected to national interests. Meanwhile, public health engagement justified on purely humanitarian grounds might fail to garner sufficient political and public support. A deliberative democratic approach based on best available scientific evidence suggests that stakeholders economize on moral disagreement and seek complementary or convergent approaches when possible. ${ }^{23}$ As a process of reaching consensus for decision making, democratic deliberation is well-suited to public health emergency preparedness because it fosters publicspirited perspectives and generates decisions that can be revisited in light of new information and engagement with specific affected communities.

Policies that employ a deliberative democratic approach need appropriate time to seek a plurality of views, encourage reflection, and establish an atmosphere for respectful exchanges of ideas as well as public-minded policies that articulate common ground. ${ }^{24}$ Public health professionals have demonstrated that such public engagement can help direct pandemic planning efforts. ${ }^{25}$ For example, a group in Minnesota engaged the public in ethical planning for managing scarce patient resources in the case of a severe influenza pandemic, resulting in development of useful guidance through an ethical framework that helped guide the Minnesota Department of Health's response to the 2009 influenza $\mathrm{A}$ (H1N1) pandemic. ${ }^{26}$ Early public engagement should be based on broad and active involvement of members of the public. ${ }^{27}$ By employing fair and respectful discussions that encourage providing reasonable grounds for justifying a decision, informed deliberation can foster the perceived legitimacy of the decisions that result. ${ }^{28}$

Democratic deliberation as a process can be particularly challenging in the midst of and in the immediate aftermath of a crisis. But, public engagement 
in some form is critical during emergencies. Such engagement is undoubtedly complicated by rapidly changing circumstances and information, uncertainty, and urgency. At such times, transparency is especially important for instilling public trust while policies are implemented and revised in light of their impact on affected communities. Public health successes reveal that acknowledging the tension between principal values, such as freedom and health, can foster consensus building and highly collaborative partnerships between civil society groups and public health organizations. For example, ongoing and successful collaborations have been forged between public health professionals working on human immunodeficiency virus/acquired immunodeficiency syndrome (HIV/AIDS) prevention and treatment in conjunction with advocacy communities. ${ }^{29}$ However, many of these relationships took years or even decades to build. ${ }^{30}$ Although the public health response, and best method of community engagement, will vary during different outbreaks, the lessons from previous successes and failures should always be relied upon to guide open and transparent public engagement during epidemics.

"[W]hen public health officers change their path in midstream, it's not because they're flipflopping as politicians are often accused of. They're actually being good doctors. When you're seeing a patient individually at the bedside and something goes awry from one hour to the next, you change your plan. And similarly, public health is a patientdoctor relationship writ large. And when you see new data coming in, you change your plan, and then you move accordingly."

Markel, H., George E. Wantz Distinguished Professor of the History of Medicine; Founding Director, Center for the History of Medicine; Professor of Pediatrics and Communicable Diseases; Professor of Psychiatry, Professor of Health Policy and Management, Professor of History, Professor of English Literature and Language University of Michigan. (2015). Historical, Sociological, and Legal Perspectives on U.S. Policies Intended to Prevent Ebola in the United States. Presentation to the Bioethics Commission, February 5. Retrieved February 18, 2015 from http://bioethics.gov/node/4593.

\section{The Current Ebola Epidemic}

Global and national public health institutions, in many cases, were slow to recognize or respond to the current Ebola epidemic for varied reasons. ${ }^{31}$ As has been observed throughout history, the beginnings of major epidemics can be slow and confusing and are often only recognized in retrospect. ${ }^{32}$ Vital epidemiological and clinical information about Ebola and the western African epidemic was incomplete and rapidly changing. ${ }^{33}$ Weaknesses in global and local public health governance and infrastructure also slowed action. ${ }^{34}$ The recognition of and response to an epidemic is affected by the current state of knowledge about the pathogen and its effects; the biological nature of the 
"Ebola is really version 3.0 of what we've been seeing for the last 50 years.... [M]any people don't realize it, but this is not the first time we've seen massive disease rise out of conflict. We saw it with sleeping sickness in Angola and Democratic Republic of Congo where 300,000 people died every year for more than a decade, but it went unseen because there were no journalists there.... [I]t would be nice if for once the world could be proactive in this. When you see an area of extreme conflict to recognize that a horrific infectious disease/tropical disease outbreak will surely follow."

Hotez, P., Dean, National School of Tropical Medicine; Professor, Departments of Pediatrics and Molecular Virology \& Microbiology, Baylor College of Medicine; Endowed Chair of Tropical Pediatrics, Texas Children's Hospital; President, Sabin Vaccine Institute. (2015). Public Health Perspectives on the Current Ebola Epidemic in Western Africa. Presentation to the Bioethics 2015 from http://bioethics.gov/node/4591. Commission, February 5. Retrieved February 18,

disease; and the social, cultural, and political contexts in which it occurs.

During this Ebola epidemic, context has been extremely important. In Guinea, Liberia, and Sierra Leone-where 23,539 total cases have occurred and 9,541 people have died (as of February 21, 2015)_Ebola has overwhelmed fragile health systems and jeopardized the political and economic infrastructure of countries just beginning to regain their footing after years of war. ${ }^{35}$ In the United States, the limited cases sometimes generated widespread fear, unflattering reactions, and governmental responses that some argued were actually focused on addressing political implications of such public reactions as opposed to the underlying health concerns themselves. ${ }^{36}$

Ebola is indeed frightening. No vaccine against the virus or effective pharmacological cure currently exists. ${ }^{37}$ Treating individuals suffering from Ebola generally involves replacing profound loss of bodily fluids and salts; treating co-infections as well as other infections to which the virus makes individuals susceptible; and addressing symptoms, such as pain. ${ }^{38}$ The nature and quality of this supportive care varies widely, depending on context. ${ }^{39}$ In some settings, merely providing oral rehydration and relief of symptoms can be challenging, whereas in high-technology settings, support might include such interventions as renal dialysis and mechanical ventilation in addition to oral rehydration. ${ }^{40}$ Combating an Ebola epidemic at the community or population level involves implementation of fundamental public health epidemic control techniques, including tracing infected persons' contacts, disease surveillance, community engagement, and health care and community infection control measures. ${ }^{41}$ 
The Ebola virus is not transmitted through the air, like influenza or tuberculosis, or transmitted before symptoms appear, like measles or HIV. Critically, Ebola is transmitted through close contact with bodily fluids of infected persons only after they have developed symptoms. Consequently, it disproportionately infects health care and burial workers as well as family caregivers. ${ }^{42}$ Individuals caring for persons with such symptoms as diarrhea, vomiting, and bleeding; performing invasive procedures; transporting infected patients; or preparing the deceased for burial can come into contact with infected bodily fluids. The necessary infection control-the most visible part of which is the "space-suit" personal protective equipment-requires both skill and stamina on the part of the wearer; can be frightening for health care workers, patients, their families, and communities; and can be limited in supply. ${ }^{43}$

Ebola's disproportionate impact on health care workers and health care infrastructure is particularly devastating in the most affected countries. ${ }^{44}$ There, hundreds of health care workers have died from Ebola. ${ }^{45}$ These deaths represent a substantial loss to countries already facing a shortage of health care workers, in part because of recruitment and emigration of health care workers to high-income countries even before the epidemic. ${ }^{46} \mathrm{~A}$ recent analysis determined the estimated incidence of Ebola to be approximately 100 times higher among health care workers compared with non-health care worker adults in Sierra Leone. ${ }^{47}$ In Liberia, another analysis of Ebola infection among health care workers revealed the majority of cases to be in health care facilities not solely dedicated to treating Ebola (mostly hospitals), highlighting the risks health care workers face providing any kind of care. ${ }^{48}$ The deaths of health care leaders, such as Dr. Sheik Humarr Khan in Sierra Leone-a global expert in viral hemorrhagic fevers-illustrate this tragedy in a very public way. ${ }^{49}$

\section{DR. SHEIK HUMARR KHAN}

Dr. Sheik Humarr Khan was a worldrenowned expert on the clinical care of viral hemorrhagic diseases and chief of the Kenema Government Hospital Lassa Fever ${ }^{50}$ Ward in Sierra Leone, where he succeeded the previous director, Dr. Aniru Conteh, who died from Lassa fever in 2004. ${ }^{51}$ An infectious diseases physician and virologist, Khan was both an active clinician and a researcher. ${ }^{52}$ He died from Ebola on July 29, 2014, at age 39. He was a coauthor on an important 2014 Science paper about the origins of the current outbreak, as well as a New England Journal of Medicine article describing clinical outcomes in individuals with Ebola in Sierra Leone, both published after he and several of his coauthors died of Ebola. ${ }^{53}$ 
Some individuals recover from Ebola. For example, all but one of the medically evacuated U.S. health care workers survived (although these patients received more advanced medical care and had higher baseline levels of health than the majority of Ebola patients in western Africa). The one medically evacuated patient who died, a Sierra Leonean surgeon and U.S. permanent resident who contracted Ebola while working on epidemic response in Sierra Leone, was suffering from an advanced stage of illness when he arrived in the United States for treatment. ${ }^{54}$

Data from the current epidemic are incomplete, making estimates of its case fatality rate (the percentage of persons with a disease who die from it) subject to imprecision and differing interpretations. ${ }^{55}$ However, many of the estimates are within the range of the case fatality rates observed in previous Ebola epidemics, particularly those associated with the Zaire ebolavirus - the most deadly strain and the one responsible for the current outbreak. ${ }^{56}$ A January 16, 2015 analysis by the European Centre for Disease Prevention and Control indicates a cumulative case fatality rate in Guinea, Liberia, and Sierra Leone among hospitalized patients for the current outbreak between 57 and 60 percent. ${ }^{57}$ Other scholars have calculated a case fatality rate in the current epidemic of 60-70 percent, adjusted for delays between disease onset and final outcome. ${ }^{58}$

Since the first documented outbreak in 1976, in what is now the Democratic Republic of the Congo (then Zaire), Ebola-like so many infectious diseaseshas both thrived in and exacerbated existing limited health infrastructure, poverty, and civil and social unrest. ${ }^{59}$ The most affected countries in this epidemic_-Guinea, Liberia, and Sierra Leone-are among the poorest in the world, with few resources devoted to health in the face of many long-term health challenges. These challenges include high infant and child mortality, psychological consequences resulting from years of war and displacement, endemic malaria, and a high burden of neglected tropical diseases. ${ }^{60}$ Each of these countries has a distinct historical, political, economic, and sociocultural context, which might help explain, for example, why the epidemic is unfolding differently in Guinea than in Sierra Leone. ${ }^{61}$ Among the commonalities in the most affected countries is a recent history of civil war and violence, leading to complex regional conflicts. ${ }^{62}$ For example, in Liberia, two civil wars beginning in 1989 destabilized the country. ${ }^{63}$ In 2002, Sierra Leone emerged from a decade-long civil war, which displaced 500,000 civilians and 
destroyed much of the country's infrastructure. ${ }^{64}$ Although Guinea did not have its own civil war, persons displaced from the Liberian and Sierra Leonean civil wars fled there, placing economic burden on the country and generating ethnic tension. ${ }^{65}$ In all cases, the Ebola epidemic is directly and indirectly exacerbating the societal and health challenges each of these countries face. Catastrophic health, social, and economic effects are emerging, including food insecurity, unemployment, orphaned children, disruptions to education, and diversion of resources from other pressing health needs, such as malaria. ${ }^{66}$

\section{Ebola in the United States}

Although the United States had concerns in some official quarters for several months-particularly among those who had longstanding experience addressing Ebola outbreaks-U.S. governmental, public health, media, and public attention to the western African Ebola epidemic intensified with the medical evacuation of two Ebola-infected American medical missionaries in August 2014. ${ }^{67}$ During the period that immediately followed, U.S. attention focused on concerns that included the need for a more robust response, the possible danger presented by bringing these health workers to the United States, and the use of experimental treatments such as ZMapp ${ }^{\mathrm{TM}}$. ${ }^{8}$ Several of these concerns were cast in explicitly ethical terms, such as whether U.S. health care workers should receive experimental clinical treatments when those in western Africa were not. ${ }^{69}$
"[The Sierra Leonean government has] canceled every alternative social safety net program in the country. If you [were] not directly dealing with Ebola, you were told your program had to shut down. So this meant that people who had other diseases,... women and girls....with fistulas, they were all sent home.... In 0ctober while I was [in Sierra Leone], 100 percent of reproductive health centers had been shut down. This was at the peak of it. So pregnant women were suffering.

And the worst part [was that in Sierra Leone]..., we don't have a savings economy. When I was a kid, we went to school. After school, we went to the markets.... You buy something, and then you come home and cook. Now, they've shut down the entire country. They've quarantined every community, and this has been going on... since May [2014] in Sierra Leone.... The people that suffered the most-and I want to just highlight some of the marginalized communities-were the poorest of the poor... I met many, many communities that were desperate."

Bah, C., Youth Engagement Officer, A World at School; Chair, Youth Advocacy Group, Global Education First Initiative. (2015). How U.S. Public Attitudes and Policies Intended to Prevent Ebola in the United States Impact Affected Communities. Presentation to the Bioethics Commission, February 5. Retrieved February 18, 2015 from http://bioethics.gov/node/4592. 


\section{U.S. PUBLIC ATTITUDES ABOUT EBOLA: AUGUST 2014, OCTOBER 2014, AND JANUARY 2015}

The Harvard School of Public Health and Social Science Research Solutions conducted a nationally representative telephone poll of 1,025 adults during August 13-17, 2014 (after the medical evacuation to the United States of health care workers with Ebola virus disease). ${ }^{70}$

- Sixty-three percent of respondents reported very or somewhat closely following news about the Ebola epidemic.

- When asked, "Are you concerned that there will be a large outbreak of Ebola inside the United States within the next 12 months?" 37 percent of respondents reported being "very" or "somewhat" concerned.

- When asked, "Are you concerned that you or someone in your immediate family may get sick from Ebola during the next 12 months?" 25 percent of respondents reported being "very" or "somewhat" concerned.

A similar telephone poll was conducted two months later, during 0ctober 8-12, 2014 (after the first imported Ebola case was diagnosed in the United States). ${ }^{71}$

- When asked, "Are you concerned that there will be a large outbreak of Ebola inside the United States within the next 12 months?" 50 percent of respondents reported being "very" or "somewhat" concerned.

- When asked, "Are you concerned that you or someone in your immediate family may get sick from Ebola during the next 12 months?" 36 percent of respondents reported being "very" or "somewhat" concerned.

Another institution, Rasmussen Reports, conducted a national telephone survey of 800 American adults with different questions. The January 2-3, 2015, survey determined that 49 percent of U.S. adults currently regard Ebola as a serious public health problem for the United States, including 14 percent who consider the problem "[v]ery [s]erious."72

Focus on Ebola in the United States-and attendant national anxietyincreased further in October 2014 with the first imported case (acquired in western Africa but diagnosed in the United States) and subsequent transmission to two U.S. nurses. ${ }^{73}$ Many public health experts considered an imported case to be inevitable, given the size and scope of the epidemic and the ability for people to travel from western Africa to the United States in less than 24 hours. ${ }^{74}$ What appeared to be more of a surprise was the lack of national and local public health preparedness, the degree to which Ebola was politicized, and the public and media reactions. ${ }^{75}$ For example, media coverage sometimes focused on theoretical—but dramatic — possible mutations of the virus rather than consistent, clear, and scientifically supported messaging regarding what is known about the virus and what U.S. residents could do to protect their 
health. ${ }^{76}$ It was also during this period that discussion and implementation of public health measures that involve monitoring and restricting movement or association (restrictive measures), including quarantine, became a focus in the United States.

Against a charged political backdrop and 24-hour media attention, frustrated public health officials struggled to convey, even before the first imported case, the low risk of individual and community transmission in the United States. ${ }^{77}$ Other public health officials downplayed uncertainties in an effort to reassure nervous health care professionals and the public. ${ }^{78}$ Some state and city governments, as well as the U.S. Department of Defense, adopted more extensive restrictive measures than those recommended by U.S. federal public health authorities. For example, the Department of Defense imposed a 21-day quarantine-a controlled monitoring policy for all Defense Department personnel, regardless of risk level, returning from Ebola-affected areas. In a Senate

"[W]hat we learned at the Dallas Morning News is that we had to have very consistent messaging and very, very repetitive messaging. So if one day I was on CNN six times talking about Ebola, six times I had to say this is how you can get Ebola, this is how you will not get Ebola. We could not overestimate how many times we'd have to repeat those messages.... I guarantee you if there is one paper out there that leaves open the minute possibility of transmission of Ebola between two nonhuman primates in a lab that may have not been through direct transmission, the public will find that one paper, and then my phone will ring off the hook at the newspaper to say, 'Why aren't you talking about it? Why have I not read about this piece of research in the newspaper?'"

Yasmin, S., Professor of Public Health, University of Texas at Dallas; Staff Writer, Dallas Morning News. (2015). How U.S. Public Attitudes and Policies Intended to Prevent Ebola in the United States Impact Affected Communities. Presentation to the Bioethics Commission, February 5. Retrieved February 18, 2015 from http://bioethics.gov/node/4592.

Appropriations Committee hearing on November 12, 2014, the Secretary of the U.S. Department of Health and Human Services, Sylvia Burwell, explained that U.S. military policy for quarantine of its personnel "was not based on the science. This was based on the management of the force and the forces' desires." 79 


\section{Analysis and Recommendations}

This global public health emergency-and our societal response to the perceived threat and reality of limited cases of Ebola arriving on our shores-has forced us as a society to revisit fundamental questions about when health crises in other countries become our shared moral concern, and has illuminated shortcomings in our public health and ethics preparedness infrastructure. ${ }^{80}$ Because the United States has both ethical and prudential reasons to engage in promoting global health and to participate in global responses to public health emergencies now and in the future, ensuring that public health preparedness includes a strong component of ethics preparedness is imperative. Strengthening local and regional public health infrastructure to address ongoing public health problems can serve to mitigate conditions that make public health emergencies more likely and, when they do occur, less likely to have devastating long-term health and societal implications ${ }^{81}$ Public health preparedness that focuses on broad capacity building will enhance the ability and flexibility of governments and institutions to respond to health emergencies because many important features of any particular health emergency will be unknown before it occurs.

\section{Recommendation 1}

In an interconnected world, for ethical reasons and to protect national interests, the U.S. government has a responsibility to engage in preparedness and to participate in coordinated global responses to public health emergencies.

Strong international and U.S. federal public health infrastructures are essential for responding effectively to public health emergencies and their short- and long-term consequences. ${ }^{82}$ As a key international public health organization, the World Health Organization (WHO) is well-positioned to provide both strong global coordination and direct on-the-ground support before, during, and after public health emergencies. However, WHO is underfunded and its effectiveness hampered by politicization and an unwieldy organizational structure and bureaucracy_vulnerabilities the current Ebola epidemic has underscored. ${ }^{83}$ Similarly, the Ebola epidemic has highlighted strengths and weaknesses in U.S. federal public health governance and infrastructure. U.S. 
federal public health agencies and state and local health departments also have faced declining funding, as well as their own bureaucratic and organizational challenges to coordinated public health emergency response, both domestically and globally. ${ }^{84}$ In addition, although philanthropic and other nongovernmental organizations play important complementary roles in global health, they cannot replace government-led public health efforts because they generally lack both its broad mandate as well as the legal authority to impose measures such as quarantine when warranted.

\section{Recommendation 2}

The United States should strengthen key elements of its domestic and
"What struck me during [the Ebola outbreak of 2001] was our absolute inability to communicate key concerns and to work with the community to control outbreaks. We lacked the vocabulary and the tools to negotiate culture, superstition, and distrust. Moreover, the fact that it took four months for the information about the outbreak to travel from [Africa] to Geneva and then to Amsterdam indicates how broken the national health system, and indeed the international response mechanism, was. Twelve years later, not much has changed in the national and international capacities required to respond to such an outbreak."

Karunakara, U., Senior Fellow, Jackson Institute for Global Affairs, Yale University; Assistant Clinical Professor, Mailman School of Public Health, Columbia University; Adjunct Visiting Professor, Kasturba Medical College, Manipal University. (2015). Historical, Sociological, and Legal Perspectives on U.S. Policies Intended to Prevent Ebola in the United States. Presentation to the Bioethics Commission, February 5. Retrieved February 18, 2015 from http:// bioethics.gov/node/4593.

global health emergency response capabilities. These include (1) strengthening the capacity of the World Health Organization to respond to global health emergencies through provision of increased funding and collaboration with other international, national, and nongovernmental public health organizations; (2) identifying and empowering a single U.S. health official accountable for all federal public health emergency response activities, including both domestic and international; and (3) strengthening the deployment capabilities of the U.S. Public Health Service, including by streamlining command structure for deployment and by providing appropriate resources to train and maintain skills needed for emergency response.

During public health emergencies, the success of policies grounded in the best available evidence and sound ethical principles hinge on how these policies are communicated to the public. Public health communication can increase 
transparency and accountability in public policy, educate the public, reduce fear and mistrust, and counter stigmatization during public health emergencies. An extensive and vital literature addressing risk and crisis communications provides a large body of evidence about how to convey messages effectively. For example, as has been long recognized among public health communications specialists, communication cannot be unidirectional, nor should "the public" or "the community" be considered a homogenous entity. ${ }^{85}$ The importance of engaging stakeholders as active and respected partners in communication, as well as building on ongoing relationships with trusted community members, has been repeatedly demonstrated. ${ }^{86}$ In addition, public health institutions and scientists should work with the media as much as necessary to deliver consistent and scientifically grounded messages, which should include being frank about uncertainty and the possibility of new evidence coming to light (despite the natural inclination to express confidence when reassuring anxious members of the public). ${ }^{87}$ Some commentators have noted that risk discourse in public health involves inextricably intertwined facts and norms. Effectively communicating public health risks must involve psychologically and socially mediated understandings of the magnitude, likelihood, and importance of hazards to human health or safety. ${ }^{88}$ These features demonstrate that interdisciplinary efforts can make distinctive contributions to identifying successful risk communication strategies, though more research is needed. ${ }^{89}$

Because communication efforts can be deeply connected to community acceptance and uptake of public health policies, public health communication forms an integral part of public health responsiveness - not an additional step taken after such responses are identified and implemented..$^{90}$ In addition, public health differs in key ways from individual health. Policy decisions must reflect these differences, and policy makers must educate the public about them if they are to foster public trust and uptake. ${ }^{11}$ Moreover, public health messages can play an important role in anticipating and countering the historically documented and ongoing tendency to stigmatize those most affected by or associated with a disease or an epidemic. ${ }^{92}$ 


\section{Recommendation 3}

Public officials have a responsibility to support public education and communication regarding the nature and justification of public health responses. Communication efforts should serve the following three interrelated purposes: (1) provide the public with useful, clear, accessible, and accurate information about the response, including what is known about what communities and individuals can do to protect their health; (2) provide those most directly affected by public health policies and programs with an appreciation of the values reflected in, and reasoning behind, their implementation; and (3) mitigate stigmatization and discrimination associated with many public health emergencies.

Epidemics can affect the public in unpredictable and novel ways and can reflect who we are as a nation. The Bioethics Commission envisions a future in which, when public health emergencies arise, they will be addressed with realtime integration of ethical considerations in addition to early planning. Public health professionals and institutions require responsive and comprehensive approaches that provide additional resources for grappling with the ethical dimensions of public health policy and practice.

Advisory bodies and ethics consultation services offer excellent examples of previous efforts at ethics integration; however, ethics should not be thought of as something that exists outside the established public health infrastructure. Rather, the best public health policies are guided by and embody rigorous ethical standards at all levels. Integrating ethics throughout public health emergency response can serve a problem-solving function by anticipating, identifying, and addressing ethical concerns in the early stages of emergencies. Ethics
"Since the effectiveness of interventions can only be tested during an epidemic, an appropriate framework should be set in place before epidemics occur. This framework should consider a broad range of issues including the ethics of study design, consent processes, use of experimental therapies, fast-track regulatory opinions and processes, and swift progression towards recommendations by international and national authorities. Transparency and open access to data should underpin the whole process."

Olliaro, P., et al. (2015, February 2). Ethical issues with the conduct of treatment trials for Ebola virus disease in endemic settings. Comments submitted to the Bioethics Commission, p. 4. 
integration also provides additional resources for justifying policy decisions at a time when public health expertise is at a premium.

For agile ethics integration to redound on all levels of public health, emergency planning and response must include thorough integration of ethical principles. Ethical expertise should be included in post-response effectiveness evaluations as well. Such efforts should explicitly articulate ethically based standards for public health and facilitate public health institutions and professionals in enacting policies in line with these benchmarks. Such standards also enable the public to hold political officials accountable to their duty to safeguard the public's health.

\section{Recommendation 4}

Ethical principles should be integrated into timely and agile public health decision making processes employed in response to rapidly unfolding epidemics. Qualified public health ethics expertise should be readily available to identify ethical considerations relevant to public health emergencies and responses in light of real-time available evidence. As one part of ethics integration into preparation for and implementation of public health emergency response, a single U.S. health official accountable for all federal domestic and international public health emergency response activities should also be accountable for ethics integration as an essential facet of public health emergency response. 


\section{PART II}

Health Planning and Response in Context 


\section{QUARANTINE AND OTHER RESTRICTIVE MEASURES DURING PUBLIC HEALTH EMERGENCIES}

he current Ebola epidemic in western Africa and the related U.S. experience
with cases within its borders highlights both the public health importance and ethical and social complexities of epidemic control measures that involve restricting movement or association. Similar to other aspects of the epidemicfrom how our nation provides assistance to affected countries to the attitudes that shape treatment of health care workers and members of the African diaspora who live in the United States-our obligations to each other urge us to consider the least restrictive means of effective protection.

\section{Overview of Restrictive Public Health Measures}

Restrictive public health measures are aimed at controlling communicable disease at the individual or community level, but the measures differ in key ways.

- Isolation refers to separation of those infected with or exhibiting symptoms of a communicable disease. ${ }^{93}$ In the case of Ebola, as with other infectious diseases, optimal and logistically practical isolation and related infection control procedures vary by context. ${ }^{94}$ For example, the high-level U.S. biocontainment units at the National Institutes of Health (NIH) (Bethesda, Maryland), Emory University Hospital (Atlanta, Georgia), the University of Nebraska (Lincoln), and Saint Patrick Hospital (Missoula, Montana) have highly specialized and elaborate infection control procedures unavailable in most other environments (including many hospitals in the United States). ${ }^{95}$ Appropriate isolation of symptomatic Ebola patients and related infection control procedures are achievable, however, in many settings, including in western Africa. ${ }^{96}$

- Quarantine refers to separation of persons exposed to but not exhibiting symptoms of a communicable disease. ${ }^{97}$ Quarantine can occur in different settings, including the private home of the exposed person or in dedicated facilities. ${ }^{98}$ For example, Kaci Hickox, an asymptomatic Médecins Sans Frontières (Doctors Without Borders) nurse returning from serving in western Africa, was detained for three days in a tent outside Newark Liberty International Airport. Upon her release, she was ordered by her home state of Maine to remain quarantined until 21 days (the incubation period for Ebola) 
after her last contact with patients. She did not have, nor was she subsequently diagnosed with, Ebola. ${ }^{99}$

- Travel restrictions can take different forms, ranging from entry or exit screening at airports, ports, and borders, to travel bans that prohibit entry of travelers from or originating at an area associated with communicable disease. For example, during the current Ebola epidemic, several countries imposed travel bans on individuals from western Africa, and considerable debate occurred in the United States about similar measures, particularly after the first imported case in October 2014. ${ }^{100}$ At that time, the Centers for Disease Control and Prevention (CDC) and Customs and Border Protection (U.S. Department of Homeland Security) implemented more intensive medical entry screening at the five U.S. airports that receive most flights originating in western Africa. Later that October, CDC also released Interim U.S. Guidance for Monitoring and Movement of Persons with Potential Ebola Virus Exposure. ${ }^{101}$ That guidance recommends that such monitoring and restrictive measures be deployed differently depending on defined risk categories. ${ }^{102}$

- Social distancing measures encompass wide-ranging actions to limit contact between persons to mitigate communicable disease transmission. In addition to quarantine and travel restrictions, which are sometimes classified as social distancing, these measures include cancellation of mass gatherings, school closures, and changed work practices such as working from alternate work sites.

An important dimension of all restrictive measures is whether they are voluntary or compulsory. In the United States, both state and the federal governments have constitutional authority to implement quarantines: states through their inherent police powers stemming from the Tenth Amendment to the U.S. Constitution and the federal government through its regulation of interstate commerce as codified in the Public Health Service Act. ${ }^{103}$ However, the power of federal, state, and local government to institute quarantine is limited by Fifth and Fourteenth Amendment due process protections (i.e., that the government cannot take a person's "life, liberty, or property, without due process of law"). ${ }^{104}$ Courts tasked with reviewing quarantine regulations scrutinize both the substantive and procedural protections provided. In a public health context, the requirements of substantive due process include 
(1) a demonstrated public health necessity, (2) an effective intervention, (3) proportionality in the tailoring of the intervention, and (4) a measure that is the least restrictive in infringing on individual rights and that does not inflict unnecessary harm. ${ }^{105}$ Procedural due process protections typically include (1) reasonable and adequate notice to the person affected by the government's proposed action, (2) an opportunity to be heard at a reasonable time and manner, (3) access to legal counsel, and (4) a final administrative decision subject to review in a court of law by an impartial decision maker. ${ }^{106}$

\section{Ethical Considerations Regarding Quarantine and Other Restrictive Measures}

Restrictive measures raise important ethical questions about how governments should exercise public health powers to limit the liberties of some for the protection of others. Approaches have generally converged around the following principles or conditions under which liberty-restricting measures can be justified.

- The harm principle: Given the fundamental importance of civil liberties, such freedoms, including freedom of movement, should only be restricted on the basis of the strongest ethical justification. Longstanding ethical traditions support measures to restrict the liberty of an individual or a group to prevent harm to others. ${ }^{107}$ This is known as the harm principle, and its strongest expression can be found in the writings of John Stuart Mill, who wrote that "the only purpose for which power can be rightfully exercised over any member of a civilized community, against his will, is to prevent harm to others." ${ }^{108}$ The harm principle can be further refined by specifying that the restriction should be effective at preventing the harm in question. In certain public health ethics frameworks, this condition of effectiveness is considered a separate principle or value called evidence-based action. ${ }^{109}$

- The principle of least infringement: This principle reflects the importance of minimizing impingement on individual liberties. After a public health intervention's effectiveness has been evaluated, options also must be evaluated and a determination made that no less-intrusive measure would be equally effective at preventing the harm. ${ }^{110}$ In conjunction with the harm principle, these two principles ensure that public health measures that restrict the liberty of individuals or groups are used only when ethically and empirically justified. 
- Beneficence and non-maleficence: Although the principle of beneficence (to promote benefit) and its corollary, non-maleficence (to do no harm), are often recognized in clinical and research ethics as complementary precepts to minimize risk and promote wellbeing, such attention to consequences is also important in public health ethics. As public health authorities consider restrictive measures, they must maintain the ability to modify implementation to reduce risks and promote wellbeing. With respect to restrictive measures, the consequentialist considerations of public health fall under the specified principle of proportionality. Proportionality requires that the probable benefits of a restrictive measure, taking into consideration any probable negative effects, are sufficient to justify any burdens, including a restriction of liberty. ${ }^{111}$

- Reciprocity: Even when justified on grounds of public health necessity, restrictions on liberty can constitute a burden to members of the public. The principle of reciprocity requires that those who bear such burdens to protect the public's health are supported by society and through public agencies and policies. ${ }^{112}$ Reciprocal support might include health care; protection from further exposure; access to food, clothing, and shelter; means of communicating with loved ones; and compensation for lost income. ${ }^{113}$ If quarantine or isolation of children is necessary, special exigencies, such as ensuring access to parents or guardians, should be considered. ${ }^{114}$ The level and kind of support is context-specific and can depend on the size of the population affected by the quarantine.

- Justice and fairness: Justice and fairness calls for respect for the rights and liberties of health care professionals and others who have come into contact with individuals with Ebola. In accordance with the requirements of distributive justice, the benefits and burdens of public health responses should not fall disproportionately on particular individuals or groups. Disparate socioeconomic conditions can render some populations more susceptible both to health emergencies and also to exploitation, making such communities a principal focus for public health response efforts. Such conditions create potential for restrictive measures to stigmatize those who fall within their scope, requiring a heightened attention to designing interventions in ways that avoid exacerbating existing social injustices. ${ }^{15}$ 
"[W]hen [Ebola] hit us, [the Liberian diaspora community] were targeted by our neighbors.... [If you were] on the ferry or the train, people pulled away from you because of your accent.... [T]hey were afraid of contracting the virus from you. And so I had to....get in the street and try to tell people, no, this is not what it's like. You don't just contract a virus because the person has an African accent or because they are from that part of the country or of the world.... I was in the street [when a guy saw] me, yelling at me, 'Take yourself back to Africa with your Ebola virus!' So we had to come out with a statement.... I'm an African, I'm not a virus. I'm a Liberian, and I'm not a virus."

Bestman-Yates, 0., President, Staten Island Liberian Community Association (SILCA). (2015). How U.S. Public Attitudes and Policies Intended to Prevent Ebola in the United States Impact Affected Communities. Presentation to the Bioethics Commission, February 5. Retrieved February 18, 2015 from http://bioethics.gov/node/4592.

\section{Lessons Learned: Past and Present Public Health Use of Restrictive Measures}

Similar to epidemics that have come before, the current Ebola epidemic reveals how social perceptions of infectious diseases can lead to unethical infringement of civil liberties and stigmatization of the ill, those who treat them, and those who otherwise come to be associated with them. ${ }^{116}$ Officials implementing restrictive measures should take into account important lessons from the past that illustrate how already marginalized groups can become targets for the misuse of public health restrictive measures. In this arena,

public health experts and other scholars have extensively analyzed stigma and discrimination. ${ }^{17}$ Many scholars have thoroughly documented how stigma is a major social determinant of health, both stemming from and exacerbating individual health problems and broader health disparities. ${ }^{118}$

Examples from the current Ebola epidemic include instances in which those from affected countries, and sometimes anyone presumed to be African, have been stigmatized in the United States. For example, in October 2014, a Texas community college stopped admitting students "from countries with confirmed Ebola cases." ${ }^{119}$ In December
"The concept of racial diseases combined with stereotypes about black bodies help to construct Ebola as a black disease that was especially frightening because it's so contagious, contaminating, and uncontainable. Perhaps the two words Americans associated Ebola with the most were Africa and fear. Granted, Ebola is contagious and often lethal.... But the extent to which fear 'outweighed' the scientific evidence of risk was determined by racial disease concepts, stereotypes, and assumptions."

Roberts, D.E., George A. Weiss University Professor of Law \& Sociology; Raymond Pace and Sadie Tanner Mossell Alexander Professor of Civil Rights; Director, Program on Race, Science, and Society, University of Pennsylvania. (2015). Historical, Sociological, and Legal Perspectives on U.S. Policies Intended to Prevent Ebola in the United States. Presentation to Bioethics Commission, February 5. Retrieved February 18, 2015 from http://bioethics.gov/node/4593. 
2014, two Senegalese-American children were beaten by schoolmates upon returning to New York City from Senegal. ${ }^{120}$

Guinean, Liberian, Sierra Leonean, American, and other health care professionals who have worked with Ebola-infected individuals also have faced stigma and discrimination, including special restrictive measures, finding themselves unwelcome at businesses or social events, and in extreme cases, subjected to violence. ${ }^{121}$ Health care workers encountered similar attitudes while caring for medically evacuated patients from western Africa. ${ }^{122}$ Stigmatization and its consequences can have serious repercussions for public health response efforts. For example, as some have suggested, such attitudes and behaviors could discourage health care workers from treating Ebola patients both in western Africa and the United States, with important implications for the capacity of health care teams on the ground to control the epidemic. ${ }^{123}$

\section{HEALTH CARE WORKERS AFFECTED BY U.S. PERCEPTIONS OF AND POLICIES ABOUT EBOLA}

\section{Nurse Volunteer in Sierra Leone}

"I've come back from west Africa, I've integrated back into my job..., and I get an email from the World Health Organization. And they say 'you're experienced in the treatment of this virus.... [C]an we deploy you for 10 days?'... [Y]ou decide that...socially and economically, that you could probably leave for 10 days. So you're ready to make the decision and then you know what flashes in the back of your head? Twenty-one days. Twenty-one days. And so, as a consequence...I declined - not based on economic or social issues, but based on the lack of clarity in what happens to someone when they come back after they've been in that situation."

Hurley, K., Clinical Nurse Manager, Intensive Care Unit, Providence St. Patrick Hospital. (2015). How U.S. Public Attitudes and Policies Intended to Prevent Ebola in the United States Impact Affected Communities. Presentation to the Bioethics Commission, February 5. Retrieved February 18, 2015 from http://bioethics.gov/node/4592.

\section{Physician Volunteer in Liberia}

"At times, it felt more challenging to actually coordinate our return to the United States than to do our Ebola-related work in west Africa. Returning home means not only managing risk, but also managing the perception of risks on an hourly basis.... Even though we are asymptomatic, many of us choose to see limited or no family during that 21-day period. This is not due to fear of making them sick, but rather public perceptions. We're concerned that our sibling, spouse, parent, or child will be sent home from work or from school because they have visited with us. In fact, that's why I returned to the United States the day after my large family's Thanksgiving celebration."

Henwood, P.C., Director of Global Health Initiatives, Department of Emergency Medicine; Assistant Professor, Perelman School of Medicine, University of Pennsylvania. (2015). How U.S. Public Attitudes and Policies Intended to Prevent Ebola in the United States Impact Affected Communities. Presentation to the Bioethics Commission, February 5. Retrieved February 18, 2015 from http://bioethics.gov/node/4592. 
A long history of previous and current societal efforts to grapple with epidemics, including efforts to prevent spread of HIV/AIDS, severe acute respiratory syndrome (SARS), and tuberculosis (TB), are particularly informative in relation to the current Ebola epidemic.

\section{HIVIAIDS}

In 2010, the United States lifted a decades-long travel and immigration ban for HIV-infected foreign nationals. Enacted in 1987 against a backdrop of fear and lack of knowledge about HIV/AIDS, the ban continued in spite of expert opinion that it lacked scientific rationale, wasted resources, discouraged HIV testing, and perpetuated stigma and discrimination. ${ }^{124}$ In his speech announcing the final steps to end the ban, President Barack Obama said, "[T]wenty-two years ago, in a decision rooted in fear rather than fact, the United States instituted a travel ban on entry into the country for people living with HIV/AIDS. Now, we talk about reducing the stigma of this disease-yet we've treated a visitor living with it as a threat. We lead the world when it comes to helping stem the AIDS pandemic-yet we are one of only a dozen countries that still bar people with HIV from entering our own country." 125

Recent calls for a travel ban in response to the current Ebola epidemic have evoked comparisons to the HIV/AIDS travel ban and other aspects of the response to that epidemic. As some HIV/AIDS activists have written, "History is repeating itself, as the irrational, punitive measures deployed in the AIDS epidemic 30 years ago are revived for another disease, this time a rare hemorrhagic fever responsible for only a few local cases."126

\section{SARS}

The new millennium's first pandemic from a novel pathogen, SARS (caused by infection with a particular strain of coronavirus whose other members include viruses that cause illnesses ranging from the common cold to the Middle East Respiratory Virus), emerged in 2002 in the People's Republic of China. ${ }^{127}$ Spread person-to-person primarily by respiratory droplets (produced when an infected person coughs or sneezes), SARS is infectious only when a person is symptomatic, with health care professionals at increased risk through contact with infected patients. ${ }^{128}$ 
Restrictive measures were used to control this pandemic in many settings, but took different forms and had varied levels of success, reflecting different sociocultural and political contexts. ${ }^{129}$ For example, Singapore, an affluent island city-state of approximately 5.6 million people, with a government that has been variously characterized as practicing "soft-authoritarian rule based on performance legitimacy," and "arguably the world's most effective administrative machine," 130 contained its outbreak through aggressive public health measures. ${ }^{131}$ These included a dedicated SARS hospital, thermal imaging machines intended to detect fever among individuals at airports, a SARS information television channel, and home quarantine of approximately 8,000 persons who had had contact with SARS patients. ${ }^{132}$ This mandatory quarantine was monitored and enforced through prosecution for noncompliance, electronic cameras installed in homes, and electronic tracking bracelets. ${ }^{133}$ Financial subsidies were provided to those quarantined. ${ }^{134}$ In Toronto as well as some other locations in Canada, a government considered protective of civil liberties implemented voluntary quarantine for thousands of individuals. ${ }^{135}$ Several experts have described the Canadian quarantine efforts during SARS as "inefficient" and "ineffective," noting that focusing public health efforts on isolation of symptomatic patients, limited contact tracing, and protective precautions might have been sufficient. ${ }^{136}$

During the SARS epidemic, Asians in Canada, the United Kingdom, and elsewhere faced stigma and discrimination. ${ }^{137}$ For example, CDC's Public Response Service tracked a daily sample of incoming SARS-related calls, noting questions associated with stigma and discrimination. Of the sampled calls, an average of 10 percent of callers expressed concerns related to fear, stigmatization, and discrimination. Concerns included fear of buying Asian merchandise as well as working with, living near, and attending school with Asians. ${ }^{138}$

\section{$T B$}

$\mathrm{TB}$ is one of the most common infectious diseases, and it imposes a substantial public health burden in the United States and globally. It is an airborne, contagious disease - spread through the air when an individual with TB expels bacteria, for example, by coughing. Both latent infection, in which the individual is not yet sick and cannot spread the disease to others, and active disease, in which the individual is sick and can spread the disease to others, can 
be treated by using antibiotic drugs. But the treatment is lengthy (at least six months) and challenging to complete. Treating TB is becoming increasingly difficult because of the spread of multidrug-resistant and extensively drugresistant strains. ${ }^{139}$

Federal and state governments have the authority to appropriately monitor and manage TB patients. Under federal regulation (42 C.F.R. parts 70, 71), CDC can detain and examine individuals suspected of carrying infectious $\mathrm{TB}$ who are entering the United States or traveling between states. ${ }^{140}$ In addition, state boards of health generally have the authority to provide care and isolation of individuals with communicable disease. For example, under the New York Public Health Law, if an individual with active disease is unable or unwilling to live in a manner as to not expose other persons who might be at risk of infection (e.g., family or household members) and if the individual is a danger to others, the state has the authority to commit the individual to isolation in a hospital or an established care institution. ${ }^{141}$

\section{Analysis and Recommendation}

History repeatedly demonstrates how epidemics create a climate of fear, cause disruption in the pattern of daily life, and increase our expectations of those in positions of public responsibility. The pressures that arise in such contexts can lead to use of more restrictive measures than necessary. These have included travel restrictions and quarantine-and more draconian variants, such as cordon sanitaire-despite the absence of scientific evidence or in overt challenge to expert consensus.

A society that recognizes the importance of individual freedom should expect and empower public officials to both strengthen the public health evidence base and to use that information to develop and implement public health policies leading to the least possible infringement. Public officials also should be aware of and, to the extent possible, prepare for the dynamics-including public pressures - which can lead to the inappropriate deviation from such an approach. The use of restrictive measures should be regularly reevaluated in light of new scientific evidence. 
Deliberative democratic processes reflect the importance of providing citizens with sound justifications for the policies that affect them. ${ }^{142}$ The harm principle as well as related principles of evidence-based action and least infringement reflect widely held values regarding health protection and civil liberties. Public health institutions and professionals have robust obligations to safeguard the public's health, duties that are reflected, for example, in CDC's mission to protect public health, safety, and security. ${ }^{143}$ This abiding commitment to serve the public provides the ethical grounding for restrictive measures.

\section{Recommendation 5}

Governments and public health organizations should employ the least restrictive means necessary-on the basis of the best available scientific evidence-in implementing restrictive public health measures, such as quarantines and travel restrictions, intended to control infectious disease spread. In addition, governments and public health organizations should be prepared to communicate clearly the rationale for such measures and provide ongoing updates to the public about their implementation, with particular attention to the needs of those most directly affected.

Public health is a crucial individual and collective good. When the threat of ill health and death puts a country's residents in peril, as in an infectious disease epidemic, other core public values, including individual liberties, can be legitimately curtailed. In these circumstances, a major challenge is to reassure and calm a frightened public without either unjustified restriction on liberty or understatement of risks. Justified restrictive measures must therefore meet a high standard that establishes that they are necessary for responding to the public health emergency. Together, these principles require officials to implement the least restrictive limits that are effective in controlling transmission. 


\section{RESEARCH ETHICS DURING PUBLIC HEALTH EMERGENCIES}

Dublic health emergencies can complicate ethical concerns common to the 1 conduct of clinical research. The fear and desperation associated with epidemics, coupled with a heightened sense of urgency, raise challenges for the way in which ethical principles for human subjects research are interpreted and practically applied during a public health emergency. In this section, the Bioethics Commission considers two research ethics concerns prominent in the current Ebola epidemic: the use of placebos in clinical trials for Ebola vaccines and treatments; and the collection, storage, and international sharing of biospecimens for current and future research.

\section{Clinical Trial Design and Use of Placebos}

\section{Introduction and Background}

Although public health and clinical measures_-including health care facility infection control, contact tracing, community education, and supportive care for persons with Ebola-are crucial in addressing the epidemic and its effects, new interventions to prevent and treat Ebola are also desperately needed. To establish the safety, efficacy, and effectiveness of such interventions in contexts where Ebola outbreaks occur, they need to be tested during an epidemic. ${ }^{144}$ As a result, large clinical trials are currently planned or underway in Ebola-affected countries in western Africa to evaluate new Ebola vaccines and pharmacological treatments. ${ }^{145}$

\section{RANDOMIZED CONTROLLED TRIALS}

Randomized controlled trials are widely considered to provide the most credible scientific evidence of the safety and efficacy of preventive or therapeutic clinical or public health interventions, although they are not always optimal, feasible, or ethical in every context, and the results can be difficult to extrapolate to nonresearch contexts. ${ }^{146}$ The design of randomized controlled trials involves assigning research participants, by chance (randomly), to one of two or more groups, each receiving a different "intervention condition," such as an experimental drug or no experimental drug or placebo (an inactive substance used for comparison that appears as much as possible identical to the experimental intervention) and a set of standard health services. At the end of the study, data from each group are analyzed and compared to answer questions set at the outset of the trial-for example, whether the drug is safe or works to alleviate the symptoms of or cure a particular illness. ${ }^{147}$ 
These studies raise difficult ethical, scientific, and practical questions about how best to design and conduct research during a public health emergencyparticularly in a context characterized by poverty, vulnerability, and limited infrastructure. One question concerns whether conducting a randomized placebo-controlled trial to evaluate new preventive or therapeutic interventions for Ebola is ethically appropriate.

In this section, the Bioethics Commission highlights two differing perspectives on this question: (1) that the priority for clinical research in the Ebola context should be to identify safe and effective interventions as efficiently and reliably as possible, and that randomized placebo-controlled trials are the best way to achieve this goal; and (2) that the priority for clinical research in the Ebola context should be to provide access to the potential benefits of experimental interventions to as many participants as possible using scientifically valid research designs. In its analysis, the Bioethics Commission underscores ethically relevant aspects of conducting clinical research in the current Ebola epidemic that might help address the tensions between these two perspectives while highlighting the importance of considering a range of trial designs-recognizing that very different concerns arise during trials of vaccines involving healthy volunteers and of treatments for research

"So this is again a classical ethical tension that...thoughtful people have written about literally for decades. It's the ageold tension of a randomized trial where on the one hand, it is in our ethical and human best interest to have an efficient and valid [treatment] trial where we learn as quickly as possible with methods we can rely on whether the experimental intervention works or not, and this equally profoundly important need for us always to [recognize] that there are human beings behind [this research] who are sick and desperately want and deserve whatever we know to be helpful and people who understandably want access...."

Kass, N., Phoebe R. Berman Professor of Bioethics and Public Health, Department of Health Policy and Management, Johns Hopkins Bloomberg School of Public Health; Director for Public Health, Berman Institute of Bioethics. (2015). Ethical Issues Associated with Research in the Context of a Public Health Emergency. Presentation to the Bioethics Commission, February 5. Retrieved February 18, 2015 from http://bioethics.gov/node/4590. participants with an often fatal disease.

\section{The Argument for Placebo-Controlled Clinical Trials during the Current Ebola Epidemic}

Randomized placebo-controlled trials are considered the ideal scientific standard for determining the efficacy of a new treatment or vaccine. 
Researchers who support use of randomized placebo-controlled trial designs in Ebola research argue that these trials are the most efficient and powerful method for assessing the safety and effectiveness of available experimental interventions, both to protect participant and patient safety during the current Ebola epidemic and the safety of future patients. ${ }^{148}$ In addition, they raise concerns about trial designs that do not involve a placebo arm, including their vulnerability to error such that credible results are unlikely and that, in the absence of credible results, it will be difficult to determine the safety, efficacy, and effectiveness of a new intervention.

"And [the Food and Drug Administration (U.S. Department of Health and Human Services)] really put weight into speed and efficiency because we felt that we only had a small window to study the investigation of products and to learn what helps and what hurts patients, and we were hoping to make a difference in this epidemic. And if not for this epidemic, we wanted to make certain that we went into the next one with the knowledge to be able to take care of patients in the best possible way."

Borio, L., Assistant Commissioner for Counterterrorism Policy; Director, Office of Counterterrorism and Emerging Threats, U.S. Food and Drug Administration (FDA). (2015). Ethical Issues Associated with Research in the Context of a Public Health Emergency. Presentation to the Bioethics Commission, February 5. Retrieved February 18, 2015 from http://bioethics.gov/node/4590.

Alternative trial designs might lead to invalid results: Proponents of randomized placebo-controlled trials argue that the data generated by certain alternative trial designs might lack validity. ${ }^{149}$ Random assignment into treatment and control groups using a parallel controlled design is considered the ideal standard for avoiding biased or incomplete conclusions. One proposed alternative to randomizing participants into treatment and control groups is to compare those taking an experimental intervention with historical control subjects. However, validity could be threatened if the historical control subjects differ in relevant ways from those in the clinical trial—for example, if they are more ill or less ill, older or younger, are identified at a different stage of illness, received different kinds of medical care, are infected with a virus that might have mutated from past epidemics, or are different in unmeasured or unmeasurable ways. It can be challenging determining whether any observed differences that exist between the outcomes are the result of the experimental intervention or instead reflect underlying differences between the groups or changes in the disease over time. ${ }^{150}$ Multivariable statistical methods can help control for some of the known and measured differences. However, accounting for all differences, especially characteristics that are unknown or unmeasured, is impossible. 
A randomized placebo-controlled trial design allows the fundamental question posed by most clinical trials to be answered with relative confidence: Are observed differences in outcomes between participants who received the experimental intervention and those who did not attributable to the experimental intervention? As part of a sound overall research design, a placebo-controlled trial increases one's confidence in the accuracy of the answer to that question, because it offers the clearest and most direct estimate of benefit. ${ }^{151}$ Advocates of randomized placebo-controlled trials in the Ebola context argue that these trials offer the most reliable and efficient (e.g., fewest participants and shortest duration) way to identify the potential benefits or harms of experimental interventions, especially because there are almost no data on the safety and efficacy of the experimental interventions and no proven drugs or vaccines for Ebola. ${ }^{152}$

Unreliable data can jeopardize interpretation of the results: Experimental therapies often fail to deliver the benefits anticipated before a clinical trial and could even cause harm. ${ }^{153}$ Despite the urgency of a public health emergency, taking all measures possible to increase the likelihood that research results will yield a credible determination about the safety, efficacy, and effectiveness of a novel intervention is especially imperative. ${ }^{154}$ Mistakenly determining a benefit or missing a potential harm can directly hurt research participants as well as individuals who use the intervention if implemented, and can impose substantial economic costs on communities and societies. ${ }^{155}$ In contrast, failing to detect a modest but meaningful level of clinical effectiveness might deprive those in need of an intervention that can reduce suffering or improve chances of survival. ${ }^{156}$

\section{The Argument against Placebo-Controlled Clinical Trials during the Current Ebola Epidemic}

Those against the use of placebos in Ebola clinical trials argue that use of placebos would be unethical in the context of the current epidemic. With a high number of infected persons dying from the disease (estimated case fatality rates for hospitalized Ebola patients is between 57 and 60 percent ${ }^{157}$ ), randomizing individuals in a treatment trial to the placebo-control arm, in which they receive supportive care only, denies them "at least the possibility of benefit" that might result from an experimental intervention. ${ }^{158}$ For similar 
reasons, using a placebo in vaccine trials might be perceived as unethical, especially if those participating in the trial are health workers both at high risk for contracting the disease and vital to combating the epidemic. ${ }^{159}$ The central ethical concern in both of these arguments is that randomizing participants to a placebo could deny them a possible—even if remote and unknown-benefit.

In response to ethical challenges to using placebos, opponents of their use advocate alternative research designs that could provide access to experimental interventions to as many individuals as possible, while also generating scientifically adequate data about their safety and effectiveness. ${ }^{160} \mathrm{~A}$ potential benefit of alternative designs, if they are feasible, is that availability of an experimental drug might encourage individuals sick with Ebola to go to treatment centers earlier, which could both ameliorate their suffering and assist in bringing the epidemic under control. ${ }^{161}$

\section{ALTERNATIVE TRIAL DESIGNS}

Historical Control Data for Therapeutic Trials: A possible alternative to placebo for therapeutic trials is to compare results from individuals receiving the experimental therapy in the trial to results from similar individuals with the disease outside a research context. For example, researchers might gather historical data from the health records of individuals who recently had Ebola and received supportive care alone. One disadvantage of this design is that relevant differences between the historical control participants and the experimental group-for example, whether the historical control participants received the same kind of supportive care or whether there are changes in the disease course over time-might make interpretation of study results more difficult. In addition, high-quality historical data might be unavailable, particularly in the context of a public health emergency.

Adaptive Trial Design: Although there are a variety of definitions of adaptive design clinical trials, most broadly an adaptive trial design prospectively plans modification of one or more specified aspects of the study design and hypotheses based on analysis of data (usually interim data). For example, an adaptive trial might use an interim analysis of trial data to modify the randomization procedure (assigning more participants to the intervention that, in the interim analysis, is strongly suggesting superiority). Adaptive trial designs might be attractive to researchers because they can help to reduce the time and resources needed to assess experimental interventions, and might help researchers select the most promising intervention option at an earlier stage of research. Both of these possible benefits are especially relevant in a public health emergency, when having more information earlier might enable researchers to provide a promising intervention to more people, or discontinue testing of a drug that is having no effect or is harmful. However, concerns have been raised about the potential for adaptive trial designs to introduce bias or to lead to study results that are difficult to interpret. ${ }^{162}$ 


\section{Analysis and Recommendation}

Debate over the ethics of placebo use in randomized clinical trials is not new. However, that debate has focused on the ethical justifications for using placebos when there is a proven treatment for a given condition. If so, giving participants in a clinical trial a placebo means withholding a proven treatment to establish the safety and efficacy of the experimental intervention. In the case of clinical trials for Ebola interventions, however, no licensed and approved treatments exist against which experimental interventions can be tested. Therefore, the debate over placebos in this context is focused not on whether denying patients in the placebo group a proven treatment is justifiable, but rather whether those patients should have the chance of receiving a benefit from the experimental intervention. It is also possible that the experimental intervention will not benefit them or could even harm them.

In the context of this epidemic, as in a broader debate over placebos, a nuanced middle ground might be ethically preferable. In Moral Science: Protecting Participants in Human Subjects Research (Moral Science), the Bioethics Commission has supported a middle ground in the placebo debate founded in the idea that "good ethics begins with good science." 163 A clinical trial that is scientifically flawed lacks the social value that we, as a society, expect scientific studies involving human participants to have-it lacks the capacity to generate knowledge that will improve human welfare now or in the future. The social value of research is particularly significant when the

"[The National Health Research Ethics Committee of Nigeria] believe[s] that modern drug development requires randomized clinical trials as the highest level of evidence that can be brought to bear on this discussion. We believe that modern research requires these principles of research ethics that we have learned and developed over the past several years. But having said that, we also believe that these things should not be taken as doctrinaire positions that cannot be engaged with within certain circumstances and that we cannot adjust or reflect upon. And [secondly] the Nigerian ethics committee at the beginning of the Ebola epidemic issued a guidance statement that said we're going to allow the use of therapies that have not completed the standard clinical trial development pathway in the context of this epidemic and share the data...so that we can rapidly evaluate the efficacy of these interventions."

Adebamowo, C.A., Professor, Epidemiology and Public Health, Department of Epidemiology and Public Health, Institute of Human Virology, and Greenebaum Cancer Center, University of Maryland School of Medicine. (2015). Ethical Issues Associated with Research in the Context of a Public Health Emergency. Presentation to the Bioethics Commission, February 5. Retrieved February 18, 2015 from http://bioethics.gov/node/4590. 
information can only be collected during an emergency, as is the case with the Ebola epidemic. ${ }^{164}$ Without social value, nothing is to be gained by exposing research participants to any of the potential risks of participation. ${ }^{165}$ However, participants in human subjects research need to be protected from research that places the demand for scientific rigor, or for scientific advancement, ahead of the protection of research participants. ${ }^{166}$ Research participants should be treated as moral agents worthy of equal concern and respect and never reduced to "mere means" for the benefit of others. ${ }^{167}$

For the purposes of this brief, the Bioethics Commission presents four considerations that are ethically relevant to resolving the inherent tensions between choosing a research design that prioritizes efficiency and clarity in results (e.g., a placebo-controlled design that relatively quickly offers a credible determination of the safety and effectiveness of a potentially lifesaving experimental intervention) and another design that might offer a chance of benefit to more participants but could take longer, require more participants, or complicate the task of yielding interpretable results.

Differences between vaccine and treatment trials: Whereas many arguments against the use of placebo-controlled clinical trials in the Ebola context focus on the potential injustice of not offering all participants an experimental treatment against a disease with such a high mortality rate, it is important to note that the ethical challenges raised by the use of placebos in vaccine trials are different from those raised by treatment trials. For example, unlike participants in a treatment trial who are infected with a disease, participants in vaccine trials are healthy volunteers. ${ }^{168}$ They therefore do not usually have a chance of benefiting from the trial in the same way as a treatmenttrial participant would-although participants at higher risk for contracting the disease, such as health care workers and burial teams, might receive an individual benefit if the vaccine proves effective. Moreover, the recent example of experimental HIV vaccine efficacy studies paradoxically increasing the risk of HIV infection in vaccine recipients underscores the scientific and ethical rationale for the inclusion of placebo arms in trial designs for diseases for which a licensed vaccine is unavailable. ${ }^{169}$

Supportive care in treatment trials: Proponents of randomized placebocontrolled trials for experimental Ebola treatments argue that those in the placebo control group should receive the best available supportive care. 
Understanding the ethical complexities of conducting a placebo-controlled trial in the current Ebola epidemic depends in part on the interpretation of "best available." On one hand, it might be interpreted as meaning the best possible supportive care, which would require the more sophisticated interventions that can be provided in well-resourced intensive care units (such as renal dialysis and ventilators) that are rarely available in the context of the current Ebola epidemic. On the other hand, the term might be interpreted to mean local de facto care wherever the specific trial is occurring, which might be very little. ${ }^{170}$

In the context of the current Ebola epidemic, providing supportive care of the level provided to the few Ebola patients treated in hospitals in the United States and Europe is both unrealistic and impractical and could not be sustained by many of the health systems most affected by this epidemic. In addition, some treatments might actually have greater benefits in a setting with less available supportive care or only be effective in a setting with a lower level of supportive care-critical distinctions that could be lost by requiring a higher level of supportive care than is sustainable outside the trial. ${ }^{171}$ Therefore, the Bioethics Commission supports the position that the most appropriate comparator for an experimental Ebola treatment in this context is the best supportive care available and sustainable in the community in which the research is conducted and where the intervention will be used. ${ }^{172}$ Establishing whether an experimental treatment is more or less effective than available and sustainable supportive care will help these communities be better prepared for future epidemics.

It is also worth noting that even without experimental treatments to test, trials to determine what forms of supportive care are feasible, sustainable, and effective at preventing death from Ebola are crucial. For example, it is critical to examine whether and in what circumstances intravenous rather than oral rehydration is best. ${ }^{173}$ Establishing and delivering the best sustainable supportive care to all patients, whether or not they participate in a trial testing a new treatment, will promote equitable access to care.

Responsiveness: In its past work, the Bioethics Commission has emphasized not only the ethical importance, but also the many complexities of designing research that is responsive to the health needs of the community in which the 
research is conducted. ${ }^{174}$ In the context of the current Ebola epidemic in western Africa, community-level concerns that randomized placebo-controlled trials might lead to or exacerbate mistrust of health care workers, reluctance to seek medical care, or social unrest should be carefully considered when identifying responses to the needs of the host community. ${ }^{175}$ Using a no-placebo research design to test experimental treatments initially might help to build trust in research and encourage patients to seek medical care, although only if the intervention does not or is not perceived to cause additional harm. If health care workers and others at the front lines of Ebola care are reluctant to participate in trials of experimental Ebola vaccines that include a placebo-control arm, alternative trial designs might be necessary to increase the likelihood that community concerns are addressed and community members are willing to participate in research. ${ }^{176}$

Credible results: In Moral Science, the Bioethics Commission noted that although differences remain between those who argue that randomized controlled trials are the ideal standard for testing new interventions and those who advocate for alternative approaches, the overriding ethical constraint is that the design of a trial must be adequate to yield results that are amenable to definitive scientific interpretation; otherwise, the risks to participants in the research cannot be justified. ${ }^{177}$

All four factors discussed here highlight the importance, during emergencies as in all other research contexts, of choosing the trial design that will both answer the question at issue and also be ethically and practically acceptable to the community in which the research is to be conducted. Given the heightened sense of urgency for evaluating experimental interventions for Ebola, including vaccines and treatments, a range of different trial designs that will yield credible results should be considered. ${ }^{178}$ As WHO has recommended, "All scientifically recognized methodologies and study designs should be considered as ethically acceptable," provided that they consider important contextual information, such as the infrastructure and resources available at the health care facility. ${ }^{179}$ Scholars have argued that, in an emergency context, an adaptive approach to clinical trial design in which preliminary trial data are used to modify the trial as it continues is ethically preferable, if it allows researchers to evaluate the safety and effectiveness of an experimental intervention sooner rather than later; an adaptive design might also offer a methodological compromise 
between responding to urgent need and obtaining the most rigorous scientific data most efficiently. ${ }^{180}$ Adaptive approaches to trial design also have limitations, however. For example, modifying the trial in response to interim results might introduce error or bias into the study or make interpretation of the results more difficult. ${ }^{181}$ Central to the Bioethics Commission's ethical analysis is the recognition that no one clinical trial design is ethically required in the context of the current Ebola epidemic or research conducted during a public health emergency more generally. Rather, the full range of trial designs that protect and promote the welfare of participants and are capable of yielding credible and reliable results should be considered.

Concerns about the design of clinical research during a public health emergency should be understood against the backdrop of the overarching goal of effective disease management. The interventions currently undergoing testing, if they are determined to be safe and effective, might come too late for many affected by the current Ebola epidemic. ${ }^{182}$ Investments in experimental vaccines and treatments for Ebola might be more likely to benefit the affected communities in the long term than in the short term. For those currently infected with Ebola, or at risk for contracting it, good clinical care and useful public health interventions, such as contact tracing and isolation of infected individuals, are likely to be more important. ${ }^{183}$ But these interventions require substantial investments of time and money into fragile health care systems and public health infrastructure.

Ethical public health emergency response should also consider the different ethical variables of short- and long-term goals. In the short term, patient access to evidence-based supportive care and stable health care infrastructure is imperative. Clinical research should be conducted so as to contribute to better understanding the natural course of the disease, providing the best supportive care available in the host communities, and building public health and health care infrastructure. These constraints on clinical research are important to ensuring that-in an emergency context when conducting research might seem to be secondary to the more urgent tasks of containing the crisis - the basic interests of research participants are protected and, as far as possible, advanced. ${ }^{184}$ In the midst of this epidemic, providing access to experimental interventions to as many patients as possible might be less ethically vital than ensuring that those participating in research and their 
communities are benefiting from what we already know about how to control and, as far as possible, treat Ebola through supportive care. For the long-term benefit of communities likely to be affected by Ebola epidemics in the future, reliable and accurate scientific data about the effectiveness of vaccines and treatments for Ebola is critical; alongside other principal areas of research, such as factors associated with survival, disease natural history, the most effective way to deliver care from a cultural perspective, and the long-term impact of the disease on survivors and communities. Without such evidence, these and other communities might be deprived of lifesaving interventions in the next Ebola epidemic, or be economically harmed by using scarce health care resources for interventions that are ineffective against the disease.

\section{Recommendation 6}

Research during the Ebola epidemic should provide all participants with the best supportive care sustainably available in the community in which the research is conducted. Trial designs should be methodologically rigorous and capable of generating results that are clearly interpretable, acceptable to the host communities and, to the extent possible, minimize delays to completing the research. Properly designed placebo-controlled trials can meet these conditions, and innovative designs, such as adaptive randomization, ought to be considered as a means of addressing these research goals. Research teams should actively engage with affected communities while planning research to determine the trial design that best reflects these ethical and scientific requirements.

Clinical research conducted during the current Ebola epidemic should be designed to provide the greatest possible benefit to those affected now, both in terms of supportive care and access to experimental interventions; minimize time necessary to assess results; and yield reliable evidence of the safety, efficacy, and effectiveness of experimental interventions for future patients. Although the first requirement ensures that, in accordance with the principle of beneficence, research participants receive as much benefit from the research as possible, the last two requirements attempt to ensure that potential harms to both current research participants and future victims of an Ebola epidemic are minimized. 
Clinical research during a serious communicable disease epidemic creates a stark ethical dilemma: On one hand, using placebo controls appears to deny some patients the possibility-however small and uncertain-of a benefit from experimental interventions; on the other hand, research that does not yield conclusive results about an intervention's safety or effectiveness could exacerbate the tragedy of the epidemic by providing misleading and potentially harmful information. Navigating this tension requires careful analysis of the range of possible trial designs coupled with a commitment to core principles of research ethics.

\section{Collection, Use, and International Sharing of Biospecimens for Research}

\section{Introduction and Background}

Collecting and sharing biospecimens has the potential to contribute to the development of diagnostic and therapeutic agents; translation of research into clinical care; and knowledge of the etiologies, pathogenesis, and genetic determinants of disease. ${ }^{185}$ In the context of a communicable disease outbreak like Ebola, access to related biospecimens and data enables researchers to study and better understand the pathogenesis, natural history, genetic variation, and transmission of the Ebola virus and can help identify epidemiological patterns and viral mutations - critical for developing vaccines and therapeutics.

Collecting and sharing biospecimens and data from the current Ebola epidemic permits research that serves at least two purposes. First, it can help facilitate development of and access to treatments for those who have Ebola. For example, research is being conducted to assess the efficacy of convalescent blood products (biospecimens from individuals who have survived the infection and in whom antibodies have developed) to treat those with Ebola. ${ }^{186}$ Second, collection and sharing of biospecimens and data can help advance research into potential therapeutic interventions (e.g., drugs and vaccines), benefiting persons who might be affected by Ebola disease in the coming months or during future epidemics. ${ }^{187}$ However, challenges exist for the ethical and practical implementation of biospecimen research. 


\section{Ethical and Practical Challenges}

Ethical Collection of Biospecimens

Development of therapeutic interventions capable of addressing future epidemics - or capable of preventing such outbreaks from occurring-often requires access to biospecimens that can only be collected during public health emergencies. ${ }^{188}$ Given that Ebola samples are only available from infected individuals, a public health emergency is often the best and perhaps only time to advance such research. Therefore, such biospecimens are extremely valuable and must be collected ethically-mindful of the challenges of obtaining informed consent during a public health emergency and with sufficient assurances of adequate privacy protections.

Informed consent is a cornerstone of ethical research and a fundamental way that researchers demonstrate respect for persons, which recognizes the fundamental human capacity for rational self-determination and freedom from limitations that can prevent meaningful choice. ${ }^{189}$ However, obtaining informed consent for collecting and sharing biospecimens from persons with Ebola is particularly challenging. ${ }^{190}$ Individuals from whom samples are being collected are often severely ill and focused on survival. Baseline questions remain regarding the ideal form of consent-for example, whether broad consent for future uses is ethically acceptable or whether more specific consent or re-consent for future uses must be obtained. ${ }^{191}$ The Bioethics Commission has argued in Privacy and Progress in Whole Genome Sequencing (Privacy and Progress) that consent should ascertain participant preferences at the time samples are obtained for whole genome sequencing, but it recognized that circumstances exist in which broad consent at the outset of research might be a more practical solution. ${ }^{192}$ For example, new or re-consent could be impractical for Ebola research, given the limited health care infrastructure in affected areas, or such consent might be impossible given the high case fatality rate.

Moreover, the nature of the Ebola epidemic means that many potential research participants might be incapacitated and unable to consent, or they might be minors. Accordingly, to the extent samples and identifying data will be shared, proxy consent might be necessary for research use of samples. In a situation where persons ill with Ebola often are isolated from friends and family 
members (either physically or because of the high case fatality rate), it might be challenging to determine who-if anyone-can act as a proxy.

U.S. human subjects research regulations do not require informed consent in two situations of particular relevance to the current Ebola epidemic. First, U.S. research regulations do not recognize research on samples from deceased individuals as constituting human subjects research, and thus such samples are not afforded typical research protections. ${ }^{193}$ But, even though individual research participants might be deceased, they could have had values or interests regarding potential use of their specimens that, if known, ought to be respected even after their passing. ${ }^{194}$
"Ideally, clinical trial participants and patients should have the opportunity for informed consent both for storing and sharing their biospecimens. However, obtaining consent might not always be possible and, even where possible, there are some circumstances in which it could be challenging to ensure that such consent is truly informed."

Infectious Diseases Society of America. (2015, February 6). Comments submitted to the Bioethics Commission, p. 5 .

Second, U.S. regulations do not recognize research on de-identified samples or data as human subjects research warranting ethics review or requiring consent from the person from whom the sample was obtained. ${ }^{195}$ Many biospecimens that are shared internationally are de-identified in accordance with regulations (meaning that certain identifiers, including name, address, and personal identification numbers are removed), but nevertheless are shared with accompanying medical and demographic information to make the sample more useful. ${ }^{196}$

Biospecimens contain genetic information that is useful to researchers in two ways. First, sharing viral sequences allows researchers to perform genetic sequencing on the Ebola virus itself to examine viral qualities that might reveal information about mutations that affect experimental treatments or whether novel associations between changes in Ebola virus variants might be associated with disease severity. ${ }^{197}$ Sharing viral sequences has implications of reciprocity and equitable benefit, as discussed in the next section.

Second, researchers can sequence human genetic material of persons exposed to Ebola to determine, for example, whether some people are genetically more susceptible to infection or experience disease severity. ${ }^{198}$ Sharing this second category of genetic sequencing raises particular concerns about the extent 
"Without sufficient data, it may not be possible to assess and predict trends and risks in infectious diseases. It is acceptable to collect and use anonymized data for assessing and predicting trends in infectious disease without consent, as long as any invasion of privacy is reduced as far as possible."

Nuffield Council on Bioethics. (2015, February 6). Comments submitted to the Bioethics Commission, p. 5. to which individuals' data ever can be truly de-identified. ${ }^{199}$ Each whole genome sequence is unique to only one person, and recent examples establish the ability of some researchers to re-identify individuals. ${ }^{200}$ Moreover, although biospecimens or data alone might not be identifiable, the additional information with which they are shared might make samples more likely to be identifiable even if traditional identifiers are removed. In addition, both genetic and genomic sequencing of human biospecimens can reveal health information about blood relatives of research participants who have privacy and confidentiality interests of their own. ${ }^{201}$

Regardless of whether shared biospecimens and data include identifiers, the principle of respect for persons implies that biospecimens collected from persons exposed to Ebola should be covered by adequate privacy protections, which is particularly important given the stigma associated with disease. As recommended by the Bioethics Commission in its report Privacy and Progress, all persons who work with genetic and genomic data should be guided by professional ethical standards related to the privacy and confidentiality of such data. ${ }^{202}$ Ensuring that persons whose biospecimens are collected during the Ebola epidemic are afforded adequate privacy protections requires that all persons and entities handling the biospecimens have adequate data security policies in place. One such example of a policy protecting privacy is NIH's Genomic Data Sharing Policy, which promotes responsible sharing of data from genomic research and seeks to provide protections for research involving human data. ${ }^{203}$ For data submitted to NIH repositories, the policy mandates de-identification of human genomic data, review of informed consent materials to determine whether data should be shared for subsequent use, and maintenance of a tiered data distribution system. ${ }^{204}$ Requests for access to genomic data by other researchers are reviewed by NIH Data Access Committees, and approved investigators must abide by the NIH Genomic Data User Code of Conduct. ${ }^{205}$ 


\section{Equitable Benefit Sharing}

Sharing biospecimen data, especially viral sequences, raises concerns about equitable benefit sharing-concerns motivated by reciprocity and justice that imply that those who provide the biological samples used in research should not be denied access to the benefits that result from that research. Reciprocity indicates that individuals and communities who have shared their biospecimens should have access to benefits that result from such research, and justice urges us to distribute such benefits equitably. ${ }^{206}$ These ethical imperatives are more pronounced when dealing with samples collected from potentially vulnerable populations, including populations that are potentially vulnerable socioeconomically, medically (e.g., suffering from disease in the midst of an epidemic in countries with limited health infrastructure), or for other reasons.

Sharing specimens and associated data in the context of public health emergencies has, at times, been contentious precisely because of questions of benefit sharing. A recent example arose during the highly pathogenic avian influenza A (H5N1) virus pandemic in the early 2000s. In this case, Indonesia's $\mathrm{H} 5 \mathrm{~N} 1$ virus samples were considered particularly valuable in tracking the global evolution of the virus and developing pharmacological treatments against the threat. ${ }^{207}$ The Indonesian government learned that the virus samples they shared were being used by pharmaceutical companies to develop new vaccines to be sold at commercial rates—rates that the Indonesian government believed it could not afford. ${ }^{208}$ The Indonesian government responded by ceasing to share its $\mathrm{H} 5 \mathrm{~N} 1$ virus samples unless it could be assured of direct access to the benefits. ${ }^{209}$

During the 2009 influenza A (H1N1) pandemic, countries across the economic spectrum shared samples. As the pandemic spread, however, high-income countries secured large contracts for vaccines and bought virtually all the vaccine that companies were able to manufacture. ${ }^{210}$ Although the United States agreed to donate 10 percent of its vaccine purchases to WHO, it later stated that vaccines would only be donated after all U.S. residents at risk had access. ${ }^{211}$ Other countries responded similarly. ${ }^{212}$

As a way forward, WHO brokered the Pandemic Influenza Preparedness Framework in 2011, which created legally enforceable contractual obligations 
on participating parties with the aim of making vaccines available to low-income countries. ${ }^{213}$ In exchange for access to biological materials, the Framework requires researchers and manufacturers to provide an agreed-upon "percentage of vaccines, diagnostics, or pharmaceuticals to WHO's stockpile" or to grant "developing countries 'fair and reasonable' royalty-free licenses to manufacture such products." 214 The Framework also prohibits establishing intellectual property rights in biological materials transferred within the system. ${ }^{215}$ Although the Framework applies only to influenza samples with pandemic potential, similarities exist with the sharing of Ebola biospecimens that nevertheless make the Framework a useful policy example for attending to concerns of justice and reciprocity.

\section{Challenges of Conducting Research Using Ebola Biospecimens}

Conducting research using Ebola biospecimens is a highly regulated enterprise because of the infectiousness of the Ebola virus. Current U.S. regulations were designed in accordance with notions of public beneficence and non-maleficence. These principles encourage members of a society to act in ways that have potential to enhance our shared wellbeing. ${ }^{216}$ The goal of these regulations is to minimize risks from exposure to all highly infectious agents by those tasked with handling biospecimens and the public at large.

For example, in the United States, Ebola research must be performed in a laboratory with equipment, trained personnel, and procedures consistent with Biological Safety Level-4 (BSL-4)—laboratories specifically designed to prevent release. ${ }^{217} \mathrm{BSL}-4$ laboratories are expensive to build and operate and are relatively rare, seriously limiting the locations at which research using Ebola biospecimens can be conducted. ${ }^{218}$

Because of the resource-intensive nature of these requirements for collecting and testing biospecimens, much of the work must be performed in institutions that have a highly developed infrastructure. However, the current Ebola epidemic is concentrated in countries with limited research facilities, staff, equipment, and funding-making storing and conducting of research on Ebola biospecimens on the ground in western Africa impractical or impossible. ${ }^{219}$ Accordingly, research on Ebola biospecimens typically is conducted in countries not affected by the current outbreak, requiring that Ebola biospecimens be transported internationally, which is challenging. For 
example, export of Ebola samples from Sierra Leone has required approval from an ethics committee, as well as Sierra Leone's Minister of Health and President. ${ }^{220}$ Importing these samples into the United States also required a permit from CDC and passage through customs. ${ }^{221}$

Although these heightened restrictions reflect the beneficent motivation of protecting the public and researchers from inadvertent exposure to a lethal and highly infectious agent, the restrictions also serve to push research to highincome countries with the health and research infrastructure to satisfy these requirements_-potentially exacerbating existing disparities by failing to invest in less-developed country infrastructure necessary for conducting cutting-edge research and requiring assurance of later benefit sharing. ${ }^{222}$ Safety restrictions also render research using Ebola biospecimens more resource intensive and limit the locations at which Ebola research can be conducted, potentially hampering development of diagnostic and therapeutic interventions.

\section{Analysis and Recommendation}

The collection, use, and international sharing of biospecimens require that researchers and other stakeholders be ethically attuned to the challenges of collecting biospecimens during a public health emergency and ensure equitable access to the benefits that result from research using those shared biospecimens. Many individuals from whom biospecimens are collected are in the throes of Ebola disease and, because of the exigencies of the disease, might be unable to give voluntary informed consent. Sharing and storing biospecimens and associated data also raises concerns about the privacy of those who donate Ebola samples. Finally, reciprocity and humanitarian justifications encourage ensuring access to the benefits of research with all who contribute, and justice compels the equitable sharing of research benefits. 


\section{Recommendation 7}

The U.S. government should ensure that Ebola virus related biospecimens are obtained ethically, including addressing the challenges of obtaining informed consent during a public health emergency and ensuring adequate privacy protections. The U.S. government should also, in collaboration with partners, facilitate access to the benefits that result from related research to the broadest group of persons possible. This can be achieved by engaging in dialogue with global partners and working collaboratively with local scientists whenever possible to develop effective strategies for ensuring equitable distribution of the benefits of research both in the United States and abroad.

The research use of identifiable biospecimens obtained from those exposed to Ebola requires initial informed consent, consistent with U.S. federal regulations, along with approval from an ethical review committee expected to play a gatekeeping role in evaluating what research can and should be conducted. When proxy consent is given, review committees should pay careful attention to its potential limitations, including any potential conflicts of interest. In all cases, ethics review committees that evaluate requests to conduct research on samples collected abroad should familiarize themselves with the concerns distinct to the locality from which the samples are collected and, whenever possible, seek local parallel review and approval. If such locations lack an established ethics review committee structure, foreign researchers and funders alike should carefully consider additional steps to protect participants. ${ }^{223}$ Neutral third-party ethics review bodies, perhaps through WHO or another group, could help with pre-review or monitor research as local capacity is improved. ${ }^{224}$

Biospecimens collected during the Ebola epidemic are likely to be shared globally and stored in biobanks around the world. Although harmonization of privacy protections across such institutions could be challenging, those who contribute biospecimens should receive assurances of a baseline of adequate protection. These protections might be implemented technically-including use of encryption and firewalls - and through regulation or institutional policies, such as the NIH Genomic Data Sharing Policy. ${ }^{25}$ Moreover, as the Bioethics Commission stated in Privacy and Progress, researchers who work with genetic or genomic data should be guided by professional 
ethical standards regarding the privacy and confidentiality of these data. ${ }^{226}$ Participants should also be informed whenever feasible that the nature of the research and subsequent advances in technology mean that no guarantee can be made that genomic samples will remain de-identified. ${ }^{227}$

Deciding how best to provide access to the benefits that accrue from research on shared biospecimens is not easy. The U.S. government should play a leading role in establishing best practices for sharing the benefits of research for international, agency, and private agreements. It should collaborate with the communities that ought to benefit, including geographic communities affected by the current Ebola epidemic or likely to be affected in future outbreaks, local scientists conducting research on the ground, health care personnel likely to be exposed in future epidemics, and the individuals who contributed biospecimens. ${ }^{228}$ Contracts such as Material Transfer Agreements - used by both private and federal parties to establish rights and obligations concerning shared biospecimens-should include discussion of royalties, access to products that arise from research using shared samples, consultation about the ways that samples will be used, scientific credit to participating researchers, and contributions that strengthen local capacity and effective research governance mechanisms. ${ }^{229}$ 
CONCLUSION 
$\mathrm{E}$ thics preparedness sets the stage for policies formulated and justified before the need to implement them during public health emergencies. Importantly, the ways in which an epidemic unfolds can warrant revisiting policies and decisions made in advance.

An advantage of decisions that result from deliberative processes is that they can be revised. Although ethics preparedness can and ought to be a priority well in advance of public health emergencies, decisions made in advance of an emergency might require interpretation and reconsideration in light of new scientific information, fresh understandings of the moral values at stake, and other changes in the context within which the decision is made. ${ }^{230}$ For example, a new and different type of epidemic might affect stakeholders whose perspectives did not initially contribute to planning, and their interests should be considered.

“Early on, I think there wasn't enough attention paid to what the downstream impacts of [the Ebola epidemic] were going to be. For a disease [where] part of the response is making sure that people don't congregate, everything that people do-whether it's attendance for school, ability for farmers to go and farm their crops, the ability for merchandise to get in so that basic needs were available for people-all those things were disrupted, hugely disrupted in countries that have had longstanding social and economic challenges coming out of a war.... I think if we're not thinking about all of these things now, we're not going to be able to be prepared for...Ebola or the next health crisis that has impact on health. Weak health infrastructures [have] a huge impact on societies and on economies that will ultimately continue to breed these sorts of severe crises...."

Gayle, H.D., President and CEO, CARE USA. (2015). Public Health Perspectives on the Current Ebola Epidemic in Western Africa. Presentation to the Bioethics Commission, February 5. Retrieved February 18, 2015 from http://bioethics.gov/ node/4591.
In this brief, the Bioethics Commission recognizes that public health emergencies can affect everyone, and that implementing public health policies can have different implications and meaning for different individuals and communities. By articulating a vision for ethics preparedness, the Bioethics Commission recognizes the importance of multiple points of view-those of the individual and the community, of health professionals and patients, of researchers and research participants, and of members of the national and global community. Anticipatory approaches to public health ethics facilitate and promote broad and inclusive discussions about ethical and public matters and associated legal and practical considerations resulting from public health emergencies. 
Public health emergencies like the current Ebola epidemic reflect the interconnectedness of all humanity, revealing our shared vulnerability. Such interconnectedness can unite human communities in collective efforts to establish societal practices and responses that safeguard and protect the rights and interests of all. Public health emergencies also can stimulate national and global conversations about the values reflected by societal responses. Included among these conversations should be consideration of what public health problems we pay attention to and why-and whether our moral imperative to provide assistance might include shining a light on and responding to less visible or emergent problems. As individuals and as members of a global society, we have obligations to seize such moments of positive reflection and to recognize and enable practices that acknowledge and embody the moral will of pluralist communities even in the midst of crises. 
ENDNOTES 
1 Harvard School of Public Health. (2014a). Ebola Poll Topline. Retrieved February 11, 2015 from http://www. hsph.harvard.edu/wp-content/uploads/sites/21/2014/08/ebola_Topline_final_08-20-14.pdf; Harvard School of Public Health. (2014b). Ebola Poll II Topline. Retrieved February 11, 2015 from https://cdn1.sph.harvard.edu/ wp-content/uploads/sites/21/2014/10/Ebola-II_Topline_15-October-2014_final.pdf.

2 World Health Organization (WHO) Ebola Response Team. (2014). West African Ebola epidemic after one year-Slowing but not yet under control. New England Journal of Medicine, 372, 584-587; World Health Organization (WHO). (2015). Ebola Situation Report-28 January 2015. Retrieved February 17, 2015 from http://apps.who.int/ebola/en/ebola-situation-report/situation-reports/ ebola-situation-report-28-january-2015.

3 World Health Organization (WHO). (2015). Ebola Situation Report - 11 February 2015. Retrieved February 18, 2015 from http://apps.who.int/ebola/en/ebola-situation-report/situation-reports/ ebola-situation-report-11-february-2015.

4 Associated Press. (2015, January 16). School in Guinea closed amid Ebola to reopen Monday. New York Times. Retrieved February 17, 2015 from http:/www.nytimes.com/aponline/2015/01/16/world/africa/ap-af-ebola-westafrica.html?_r=0; BBC. (2015, January 19). Ebola crisis: Guinea schools reopen after five-month closure. $B B C$. Retrieved February 17, 2015 from http://www.bbc.com/news/world-africa-30879937.

5 Regan, H. (2015, February 16). Schools in Liberia reopen after a six-month closure due to Ebola. Time. Retrieved February 17, 2015 from http://time.com/3711451/liberia-schools-reopen-ebola/.

6 Foege, W., Senior Fellow, Health Policy, Carter Center; Senior Fellow, Global Health Program, Gates Foundation; Emeritus Presidential Distinguished Professor of International Health, Emory University. (2015). Public Health Perspectives on the Current Ebola Epidemic in Western Africa. Presentation to the Bioethics Commission, February 5. Retrieved February 18, 2015 from http://bioethics.gov/node/4591; Grassly, N.C. (2013). The final stages of the global eradication of poliomyelitis. Philosophical Transactions of the Royal Society of London, 368(1623), 1-14.

7 Markel, H., George E. Wantz Distinguished Professor of the History of Medicine; Founding Director, Center for the History of Medicine; Professor of Pediatrics and Communicable Diseases; Professor of Psychiatry, University of Michigan. (2015). Historical, Sociological, and Legal Perspectives on U.S. Policies Intended to Prevent Ebola in the United States. Presentation to the Bioethics Commission, February 5. Retrieved February 18, 2015 from http://bioethics.gov/node/4593; Locker, D. (2008). Social Determinants of Health and Disease. In G. Scambler. (Ed.). Sociology as Applied to Medicine, Sixth Edition (pp. 18-37). New York, NY: Elsevier; Hotez, P. (2007). Neglected diseases and poverty in "the other America": The greatest health disparity in the United States? PLoS Neglected Tropical Diseases, 1(3), e149.

8 Lakoff, A. (2010). Two regimes of global health. Humanity: An International Journal of Human Rights, Humanitarianism, and Development, 1(1), 59-79.

9 Gostin, L.O., Founding Linda D. \& Timothy J. O’Neill Professor of Global Health Law; Faculty Director, O’Neill Institute for National \& Global Health Law; Director, World Health Organization Collaborating Center on Public Health Law \& Human Rights; University Professor, Georgetown Law. (2014). Deliberation and Bioethics Education: Case Study of Public Health Emergency Response. Presentation to the Bioethics Commission, November 6. Retrieved February 11, 2015 from http://bioethics.gov/node/4323; Nagel, T. (2005). The problem of global justice. Philosophy and Public Affairs, 33(2), 113-147; Singer, P. (1972). Famine, affluence, and morality. Philosophy and Public Affairs, 1(3), 229-243.

${ }^{10}$ Sokol, D.K. (2006). Virulent epidemics and scope of healthcare workers' duty to care. Emerging Infectious Diseases, 12(8), 1238-1241; Rid, A., and E. Emanuel. (2014). Why should high-income countries help combat Ebola? JAMA, 312(13), 1297-1298.

11 Beauchamp, D.E. (1976). Public health as social justice. Inquiry, 13(1), 3-14; Powers, M., and Faden, R. (2006). Social Justice: The Moral Foundations of Public Health and Health Policy. Oxford, UK: Oxford University Press; Venkatapuram, S. (2011). Health Justice: An Argument from the Capabilities Approach. Malden, MA: Polity Press. 
12 Rothstein, M.A. (2014). The moral challenge of Ebola. American Journal of Public Health, 105(1), 6-8.

13 Watts, S. (1999). Epidemics and History: Disease, Power and Imperialism. New Haven, CT: Yale University Press; Atlas, T. (2014, October 22). Ebola fought along colonial-era lines in West Africa. Bloomberg. Retrieved February 18, 2015 from http://www.bloomberg.com/news/2014-10-22/ebola-fought-along-colonial-era-linesin-west-africa.html; Hooker, L.C., et al. (2014). Don't be scared, be angry: The politics and ethics of Ebola. Medical Journal of Australia, 201(6), 352-354; Kentikelenis, A., et al. (2015). The International Monetary Fund and the Ebola outbreak. Lancet, 3(2), e69-70.

${ }_{14}$ Rid, A., and E. Emanuel, supra note 10; Hooker, L.C., et al., supra note 13; Ciment, J. (2014, September 23). America in Africa. Slate. Retrieved February 12, 2015 from http://www.slate.com/articles/news_and_politics/ history/2014/09/ebola_in_liberia_america_owes_the_west_african_nation_founded_by_free_blacks.html; Kass, N.E. (2004). Public health ethics: From foundations and frameworks to justice and global public health. Journal of Law, Medicine \& Ethics, 32(2), 232-242.

${ }_{15}$ Pogge, T. (2002). World Poverty and Human Rights: Cosmopolitan Responsibilities and Reforms. London, UK: Polity Press.

${ }_{16}$ The White House. (2014). The Administration's Response to Ebola. Retrieved February 12, 2015 from http:// www.whitehouse.gov/ebola-response; Frieden, T. (2014, October 13). CDC Director: Why I don't support a travel ban to combat Ebola outbreak. Centers for Disease Control and Prevention Blog: Our Global Voices. Retrieved February 12, 2015 from http://blogs.cdc.gov/global/2014/10/13/cdc-director-why-i-dont-support-atravel-ban-to-combat-ebola-outbreak/; Kickbush, I. (2002). Influence and opportunity: Reflections on the U.S. role in global public health. Health Affairs, 21(6), 131-141.

${ }_{17}$ Frieden, T. (2014, October 6). Letter to the Editor of The Financial Times. CDC Director Blog-Thoughts from CDC Director Tom Frieden, MD, MPH. Retrieved February 18, 2015 from http://blogs.cdc.gov/ cdcdirector/2014/10/06/letter-to-the-editor-of-the-financial-times/.

${ }_{18}$ Yach, D., and D. Bettcher. (1998). The globalization of public health, II: The convergence of self-interest and altruism. American Journal of Public Health, 88(5), 738-741; Institute of Medicine. (1997). America's Vital Interest in Global Health-Protecting Our People, Enhancing Our Economy, and Advancing Our International Interests. Washington, DC: National Academies Press.

19 Fidler, D.P. (2003). Public health and national security in the global age: Infectious diseases, bioterrorism and realpolitik. George Washington International Law Review, 35, 787-856; Gostin, L.O., Waxman, H.A., and W.F. Foege. (2015). The President's national security agenda: Curtailing Ebola, safeguarding the future. JAMA, 313(1), 27-28.

${ }^{20}$ Kaiser Family Foundation. (2013). 2013 Survey of Americans on the U.S. Role in Global Health. Retrieved February 10, 2015 from https://kaiserfamilyfoundation.files.wordpress.com/2013/11/8508-f-2013-survey-ofamericans-on-the-u-s-role-in-global-health.pdf; Salaam-Blyther, T. (2013). U.S. Global Health Assistance: Background and Issues for the 113th Congress. Washington, DC: Congressional Research Service. Retrieved February 10, 2015 from https://www.fas.org/sgp/crs/row/R43115.pdf.

${ }^{21}$ Drazen, J.M., et al. (2014). Ebola and quarantine. New England Journal of Medicine, 371(21), 2029-2030.

${ }^{22}$ Gilchrist, S. (1995). Chapter 10: The Cordon Sanitaire-Is It Useful? Is It Practical? In J.N. Moore and R.F. Turner. (Eds.). Readings on International Law from the Naval War College Review, 1978-1994, Vol. 68 (pp. 131-145). Newport, RI: Naval War College; Mihm, S. (2014, August 17). Fighting Ebola the medieval way. Bloomberg View. Retrieved February 12, 2015 from http://www.bloombergview.com/articles/2014-08-17/ fighting-ebola-the-medieval-way; McNeil, D.G. (2014, August 12). Using a tactic unseen in a century, countries cordon off Ebola-racked areas. New York Times. Retrieved February 12, 2015 from http://www. nytimes.com/2014/08/13/science/using-a-tactic-unseen-in-a-century-countries-cordon-off-ebola-racked-areas. html?_r=0; The Cambrian. (1897). Current Events: Shotgun Quarantine. The Cambrian: A Monthly Magazine, XVII, 12. Utica, NY: Thomas J. Griffiths Publisher, p. 531.

${ }^{23}$ Gutmann, A., and D. Thompson. (2004). Why Deliberative Democracy? Princeton, NJ: Princeton University Press, p. 155.

${ }^{24}$ Presidential Commission for the Study of Bioethical Issues (PCSBI). (2010, December). New Directions: The Ethics of Synthetic Biology and Emerging Technologies. Washington, DC: PCSBI, pp. 28-30. 
25 Braunack-Mayer, A.J., et al. (2010). Including the public in pandemic planning: A deliberative approach. BMC Public Health, 10(501), doi: 10.1186/1471-2458-10-501; Baum, N.M, Jacobson, P.D., and S.D. Goold. (2009). "Listening to the people": Public deliberation about social distancing measures in a pandemic. American Journal of Bioethics, 9(11), 4-14.

${ }^{26}$ Garrett, J.E., et al. (2011). The Minnesota pandemic ethics project: Sequenced, robust public engagement processes. Journal of Participatory Medicine, 3. Retrieved February 12, 2015 from http://www.jopm.org/evidence/ research/2011/01/19/the-minnesota-pandemic-ethics-project-sequenced-robust-public-engagement-processes/.

27 Gutmann, A., and D. Thompson, supra note 23, at 7.

${ }^{28}$ Daniels, N. (2008). Just Health: Meeting Health Needs Fairly. New York, NY: Cambridge University Press.

${ }^{29}$ See, e.g., City and County of San Francisco Department of Public Health Community Health Equity and Promotion Branch Population Health Division. (n.d.) Community Collaborations. Retrieved February 12, 2015 from http://www.sfhiv.org/community-planning/; Jana, S., et al. (2004). The Sonagachi Project: A sustainable community intervention program. AIDS Education and Prevention, 16(5), 405-14.

${ }^{30}$ Roussos, S.T., and S.B. Fawcett. (2000). A review of collaborative partnerships as a strategy for improving community health. Annual Review of Public Health, 21, 369-402.

31 Farrar, J.J., and P. Piot. (2014). The Ebola emergency-Immediate action, ongoing strategy. New England Journal of Medicine, 371(16), 1545-1546.

${ }^{32}$ Karunakara, U., Senior Fellow, Jackson Institute for Global Affairs, Yale University; Assistant Clinical Professor, Mailman School of Public Health, Columbia University; Adjunct Visiting Professor, Kasturba Medical College, Manipal University. (2015). Historical, Sociological, and Legal Perspectives on U.S. Policies Intended to Prevent Ebola in the United States. Presentation to the Bioethics Commission, February 5. Retrieved February 18, 2015 from http://bioethics.gov/node/4593.

${ }^{33}$ McNeil Jr, D.G. (2014, September 5). Many in West Africa may be immune to Ebola virus. New York Times. Retrieved February 12, 2015 from http://www.nytimes.com/2014/09/06/health/ebola-immunity.html; Bellan, S.E., et al. (2014). Ebola control: Effect of asymptomatic infection and acquired immunity. Lancet, 384(9953), 1499-1500; Leroy, E.M., et al. (2000). Human asymptomatic Ebola infection and strong inflammatory response. Lancet, 355(9222), 2210-2215.

${ }^{34}$ Foege, W., supra note 6; Beaubien, J. (2015, February 6). Critics say Ebola crisis was WHO's big failure. Will reform follow? NPR. Retrieved February 12, 2015 from http://www.npr.org/blogs/ goatsandsoda/2015/02/06/384223023/critics-says-ebola-crisis-was-whos-big-failure-will-reform-follow.

35 This includes cases that are suspected, probable, and laboratory confirmed. Suspected is defined as "[a]ny person, alive or dead, who has (or had) sudden onset of high fever and had contact with a suspected, probable or confirmed Ebola virus disease (EVD) case, or a dead or sick animal OR any person with sudden onset of high fever and at least three of the following symptoms: headache, vomiting, anorexia/loss of appetite, diarrhea, lethargy, stomach pain, aching muscles or joints, difficulty swallowing, breathing difficulties, or hiccup; or any person with unexplained bleeding OR any sudden, unexplained death"; and probable as "[a]ny suspected case evaluated by a clinician OR any person who died from 'suspected' EVD and had an epidemiological link to a confirmed case but was not tested and did not have laboratory confirmation of the disease”; and laboratory confirmed cases. World Health Organization (WHO). (2015). Ebola Situation Report-4 February 2015. Retrieved February 12, 2015 from http://apps.who.int/ebola/en/ebola-situation-report/situation-reports/ ebola-situation-report-4-february-2015; Centers for Disease Control and Prevention (CDC). (2015, February 23). 2014 Ebola Outbreak in West Africa-Case Counts. Retrieved February 24, 2015 from http://www.cdc.gov/ vhf/ebola/outbreaks/2014-west-africa/case-counts.html; Salaam-Blyther, T. (2014). The 2014 Ebola outbreak: International and U.S. responses. Congressional Research Service. Retrieved February 12, 2015 from http:// digital.library.unt.edu/ark:/67531/metadc463435/m1/1/high_res_d/R43697_2014Aug26.pdf; Boozary, A.S., Farmer, P.E., and A.K. Jha. (2014). The Ebola outbreak, fragile health systems, and quality as cure. JAMA, 312(18), 1859-1860; Rashid, I. (2013). The Sierra Leone Civil War and the remaking of ECOWAS. Research in Sierra Leone Studies: Weave, 1(1), 1-21. 
${ }^{36}$ Steinhauer, J. (2014, October 19). In U.S., fear of Ebola closes schools and shapes politics. New York Times. Retrieved February 12, 2015 from http://www.nytimes.com/2014/10/20/us/fear-of-ebola-closes-schools-andshapes-politics.html.

${ }^{37}$ Cooper, C.L., and S. Bavari. (2014). A race for an Ebola vaccine: promises and obstacles. Trends in Microbiology, 23(2), 65-66.

${ }^{38}$ Schieffelin, J.S., et al. (2014). Clinical illness and outcomes in patients with Ebola in Sierra Leone. New England Journal of Medicine, 371(22), 2092-2100; Bah, E.I., et al. (2015). Clinical presentation of patients with Ebola virus disease in Conakry, Guinea. New England Journal of Medicine, 372(1), 40-47; Goeijenbier, M., et al. (2014). Ebola virus disease: A review on epidemiology, symptoms, treatment and pathogenesis. The Netherlands Journal of Medicine, 72(9), 442-448; Centers for Disease Control and Prevention (CDC). (2014). Ebola Virus Disease: Treatment. Retrieved February 12, 2015 from http://www.cdc.gov/vhf/ebola/treatment/.

39 Goeijenbier, M., et al., supra note 38; CDC, supra note 38.

${ }^{40}$ Fowler, R.A., et al. (2014). Caring for critically ill patients with Ebola virus disease. Perspectives from West Africa. American Journal of Respiratory and Critical Care Medicine, 190(7), 733-737; Connor Jr, M.J., et al. (2015). Successful delivery of RRT in Ebola virus disease. Journal of the American Society of Nephrology, 26(1), 31-37; Wolf, T., et al. (2014). Severe Ebola virus disease with vascular leakage and multiorgan failure: Treatment of a patient in intensive care. Lancet, S0140-6736(14), 62384-62389.

${ }^{41}$ Pandey, A., et al. (2014). Strategies for containing Ebola in West Africa. Science, 346(6212), 991-995; Lamontagne, F., et al. (2014). Doing today's work superbly well-Treating Ebola with current tools. New England Journal of Medicine, 371(17), 1565-1566.

${ }^{42}$ Nishiura, H., and G. Chowell. (2015). Theoretical perspectives on the infectiousness of Ebola virus disease. Theoretical Biology and Medical Modelling, 12(1), 1; Beeching, N.J., Fenech, M., and C.F. Houlihan. (2014). Ebola virus disease. British Medical Journal, 349, g7348; Chowell, G., and H. Nishiura. (2014). Transmission dynamics and control of Ebola virus disease (EVD): A review. BMC Medicine, 12(1), 196; Drazen, J.M., et al., supra note 22; Chowell-Puente, G. (2014, October 1). Ebola is no measles. That's a good thing. Slate. Retrieved February 12, 2015 from http://www.slate.com/articles/technology/future_tense/2014/10/ebola_transmission_ rate_the_virus_doesn_t_spread_as_quickly_as_measles_and.html; Kaiser Family Foundation. (2014). Ebola characteristics and comparisons to other infectious diseases. Retrieved February 12, 2015 from http://files.kff. org/attachment/ebola-characteristics-and-comparisons-to-other-infectious-diseases-fact-sheet; Nielsen, C.F., et al. (2015). Improving burial practices and cemetery management during an Ebola virus disease epidemicSierra Leone, 2014. Morbidity and Mortality Weekly Report (MMWR), 64(1), 20-27.

${ }^{43}$ Henwood, P.C., Director of Global Health Initiatives, Department of Emergency Medicine; Assistant Professor, Perelman School of Medicine, University of Pennsylvania. (2015). How U.S. Public Attitudes and Policies Intended to Prevent Ebola in the United States Impact Affected Communities. Presentation to the Bioethics Commission, February 5. Retrieved February 18, 2015 from http://bioethics.gov/node/4592; Hurley, K., Clinical Nurse Manager, Intensive Care Unit, Providence St. Patrick Hospital. (2015). How U.S. Public Attitudes and Policies Intended to Prevent Ebola in the United States Impact Affected Communities. Presentation to the Bioethics Commission, February 5. Retrieved February 18, 2015 from http://bioethics.gov/ node/4592; Martin-Moreno, J.M., Llinas, G., and J.M. Hernandez. (2014). Is respiratory protection appropriate in the Ebola response? Lancet, 384(9946), 856; International Association of Fire Chiefs. (2015, February 4). Comments submitted to the Bioethics Commission, p. 1.

${ }^{44}$ Centers for Disease Control and Prevention (CDC). (2014). Guidance on personal protective equipment to be used by health care workers during management of patients with Ebola virus disease in U.S. hospitals, including procedures for putting on (donning) and removing (doffing). Retrieved December 8, 2014 from http://www.cdc. gov/vhf/ebola/hcp/procedures-for-ppe.html; Cohen, J. (2014). When Ebola protection fails. Science, 346(6205), 17-18; Forrester, J.D., et al. (2014). Cluster of Ebola cases among Liberian and U.S. health care workers in an Ebola treatment unit and adjacent hospital-Liberia, 2014. Morbidity and Mortality Weekly Report (MMWR), 63(41), 925-929.

45 WHO, supra note 3; Matanock, A., et al. (2014). Ebola virus disease cases among health care workers not working in Ebola treatment units-Liberia, June-August, 2014. Morbidity and Mortality Weekly Report (MMWR), 63(46), 1077-1081. 
${ }^{46}$ Aiken, L.H., et al. (2004). Trends in international nurse migration. Health Affairs, 23(3), 69-77; Tankwanchi, A.B.S., Ozden, C., and S.H. Vermund. (2013). Physician emigration from sub-Saharan Africa to the United States: Analysis of the 2011 AMA physician masterfile. PLoS Medicine, 10(9), e1001513; Yasmin, S., Professor of Public Health, University of Texas at Dallas; Staff Writer, Dallas Morning News. (2015). How U.S. Public Attitudes and Policies Intended to Prevent Ebola in the United States Impact Affected Communities. Presentation to the Bioethics Commission, February 5. Retrieved February 18, 2015 from http://bioethics.gov/ node/4592.

${ }^{47}$ Kilmarx, P.H., et al. (2014). Ebola virus disease in health care workers: Sierra Leone, 2014. Morbidity and Mortality Weekly Report (MMWR), 63(49), 1168-1171.

${ }^{48}$ Matanock, A., et al., supra note 45.

49 Bausch, D.G., et al. (2014). A tribute to Sheik Humarr Khan and all the healthcare workers in West Africa who have sacrificed in the fight against Ebola virus disease: Mae we hush. Antiviral Research, 111, 33-35; Green, A. (2014). Obituary: Sheik Humarr Khan. Lancet, 384(9945), 740.

${ }^{50}$ Lassa fever is an acute, zoonotic viral disease, resulting in serious symptoms, including hemorrhaging, in 20 percent of infected individuals. An estimated one percent of infected individuals die from the disease. In western Africa, approximately 100,000 to 300,000 individuals are infected each year, with 5,000-20,000 deaths. In some parts of Sierra Leone and Liberia, an estimated 10-16 percent of persons admitted to hospitals have Lassa fever. Centers for Disease Control and Prevention (CDC). (n.d.). Lassa Fever. Retrieved February 12, 2015 from http://www.cdc.gov/vhf/lassa/resources/Lassa-FactSheet.pdf; World Health Organization (WHO). (n.d.). Lassa fever. Retrieved February 12, 2015 from http://www.who.int/csr/disease/lassafever/en/.

51 Bausch, D.G., et al., supra note 49; Viral Hemorrhagic Fever Consortium. (n.d.). Dr. Sheik Humarr Khan. Retrieved February 12, 2015 from http://vhfc.org/consortium/people/humarr-khan; Wright, P. (2004). Obituary: Aniru Conteh. Lancet, 363(9423), 1831.

52 Green, A., supra note 49; Hayden, E.C. (2014). Ebola’s lost ward. Nature, 513(7519), 474-477.

53 Gire, S.K., et al. (2014). Genomic surveillance elucidates Ebola virus origin and transmission during the 2014 outbreak. Science, 345(6202), 1369-1372; Schieffelin, J.S., et al., supra note 38; Vogel, G. (2014, August 28). Ebola's heavy toll on study authors. ScienceInsider. Retrieved February 12, 2015 from http://news.sciencemag. org/health/2014/08/ebolas-heavy-toll-study-authors.

${ }^{54}$ Harrison, C. (2014, November 17). Doctor dies in Nebraska after Ebola infection in Sierra Leone. Bloomberg. Retrieved February 12, 2015 from http://www.bloomberg.com/politics/articles/2014-11-17/ doctor-dies-in-nebraska-after-ebola-infection-in-sierra-leone/.

55 Focosi, D., and F. Maggi. (2014). Estimates of Ebola virus case-fatality ratio in the 2014 West African outbreak. Clinical Infections Diseases, doi: 10.1093/cid/ciu921; Kucharski, A.J., and W.J. Edmunds. (2014). Case fatality rate for Ebola virus disease in west Africa. Lancet, 384(9950), 1260.

${ }^{56}$ Lefebvre, A., et al. (2014). Case fatality rates of Ebola virus diseases: a meta-analysis of World Health Organization data. Médecine et maladies infectieuses, 44(9), 412-416; World Health Organization (WHO). (2014). Ebola virus disease: Fact sheet $\mathrm{N}^{\circ} 103$. Retrieved February 12, 2015 from http://www.who.int/ mediacentre/factsheets/fs103/en/.

${ }^{57}$ European Centre for Disease Prevention and Control. (2015, January 16.) Epidemiological update: Outbreak of Ebola virus disease in West Africa. Retrieved February 12, 2015 from http://www.ecdc.europa.eu/en/press/ news/_layouts/forms/News_DispForm.aspx?List=8db7286c-fe2d-476c-9133-18ff4cb1b568\&ID=1151.

${ }^{58}$ Focosi, D., and F. Maggi, supra note 55; Kucharski, A.J., and W.J. Edmunds, supra note 55.

59 Breman, J.G., and K.M. Johnson. (2014). Ebola then and now. New England Journal of Medicine, 371(18), 16631666; Palomo, A.M. (2015). Ebola: The haves and the have-nots. Journal of Public Health Policy, 36(1), 4-6; Piot, P. (2014). Ebola's perfect storm. Science, 345(6202), 1221. 
${ }^{60}$ Bausch, D.G., and L. Schwarz. (2014). Outbreak of Ebola Virus Disease in Guinea: Where ecology meets economy. PLoS Neglected Tropical Diseases, 8(7), e3056; Hotez, P.J., and A. Kamath. (2009). Neglected tropical diseases in sub-Saharan Africa: Review of their prevalence, distribution, and disease burden. PLoS Neglected Tropical Diseases, 3(8), e412; Kruk, M.E., et al. (2010). Availability of essential health services in post-conflict Liberia. Bulletin of the World Health Organization, 88(7), 527-534; World Bank. (2013). Gross domestic product 2013. Retrieved February 12, 2015 from http://databank.worldbank.org/data/download/GDP.pdf; World Bank. (n.d.). 2010-2014 Health expenditure per capita (current US\$). Retrieved February 12, 2015 from http://data.worldbank.org/indicator/SH.XPD.PCAP; World Health Organization (WHO). (2012). Guinea: Health profile. Retrieved February 12, 2015 from http://www.who.int/gho/countries/gin.pdf?ua=1.

${ }^{61}$ United Nations Development Program. (2014). Assessing the Socio-Economic Impacts of Ebola Virus Disease in Guinea, Liberia, and Sierra Leone: The Road to Recovery. Retrieved February 17, 2015 from http://www. africa.undp.org/content/dam/rba/docs/Reports/EVD\%20Synthesis\%20Report\%2023Dec2014.pdf.

${ }^{62}$ Rashid, I., supra note 35.

${ }^{63}$ Herbert, S. (2014). Conflict Analysis of Liberia. Birmingham, UK: GSDRC, University of Birmingham. Retrieved February 12, 2015 from http://www.gsdrc.org/docs/open/LiberiaCA.pdf.

${ }^{64}$ Collier, P., and M. Duponchel. (2012). The economic legacy of civil war: Firm-level evidence from Sierra Leone. Journal of Conflict Resolution, 57(1), 65-88.

${ }_{65}$ BBC. (2015). Guinea Profile [Webpage]. Retrieved February 12, 2015 from http://www.bbc.com/news/ world-africa-13442051; Blunt, E. (2001, February 13). The Guinea conflict explained. BBC. Retrieved February 12, 2015 from http://news.bbc.co.uk/2/hi/africa/1167811.stm; Blunt, E. (2000, October 23). Civil war fears in Guinea. BBC. Retrieved February 12, 2015 from http://news.bbc.co.uk/2/hi/africa/986375.stm.

${ }^{66}$ Assessment Capacities Project. (2014). Ebola in West Africa: Potential Impact on Food Security. Retrieved February 12, 2015 from http://acaps.org/img/documents/b-acaps-bn-west-africa-ebola-impact-on-foodsecurity-11-nov-2014.pdf; Center for Strategic and International Studies. (2014). Economic Impacts of Ebola. Retrieved February 12, 2015 from http://www.smartglobalhealth.org/blog/entry/economic/; Hamilton, J. (2014, November 10). Ebola today could mean illiteracy tomorrow in West Africa. NPR. Retrieved February 12, 2015 from http://www.npr.org/templates/transcript/transcript.php?storyId=362302778; Hayden, E.C. (2014). Ebola obstructs malaria control. Nature, 514(7520), 15-16; Liberia Institute of Statistics and Geo-Information Services, World Bank Group, and Gallup. (2015). The Socio-Economic Impacts of Ebola in Liberia. Washington, DC: World Bank Group. Retrieved February 12, 2015 from http://tinyurl.com/os517zv; UNICEF. (2014, September 30). Thousands of children orphaned by Ebola: UNICEF. Retrieved February 12, 2015 from http://www.unicef. org/media/media_76085.html; World Food Program. (2014). Special mVAM Regional Bulletin \#1. Guinea, Liberia and Sierra Leone: Food insecurity remains high in spite of the harvest. Retrieved December 8, 2014 from http://documents.wfp.org/stellent/groups/public/documents/ena/wfp269946.pdf.

67 Berman, M. (2014, August 5). Fear, treatment and a serum: The U.S. and the Ebola outbreak. Washington Post. Retrieved February 12, 2015 from http://www.washingtonpost.com/news/post-nation/wp/2014/08/05/ fear-treatment-and-a-serum-the-u-s-and-the-ebola-outbreak/; Breman, J.G., and K.M. Johnson, supra note 59; Butler, D. (2014). Global Ebola response kicks into gear at last. Nature, 513(7519), 469. Retrieved February 12, 2015 from http://www.state.gov/p/af/rls/fs/2014/230552.htm; French, M., and M. Sasso. (2014, August 2). First of two Americans with Ebola virus lands in U.S. Bloomberg. Retrieved February 12, 2015 from http:// www.bloomberg.com/news/2014-08-01/two-americans-with-ebola-returning-to-u-s-for-treatment.html; Koba, M. (2014, August 5). Ebola fears reach U.S. shores: Hype or real threat? CNBC. Retrieved December 30, 2014 from http://www.cnbc.com/id/101895662\#; Lancet. (2014). Ebola: A failure of international collective action. Lancet, 384(9944), 23-29; Médecins Sans Frontières. (2014). Response to west Africa Ebola epidemic remains dangerously inadequate. Retrieved February 12, 2015 http://www.doctorswithoutborders.org/news-stories/fieldnews/response-west-africa-ebola-epidemic-remains-dangerously-inadequate; U.S. Department of State. (2014, August 14). Response to the Ebola virus [Fact sheet]. Retrieved February 12, 2015 from http://www.state.gov/p/ $\mathrm{af} / \mathrm{rls} / \mathrm{fs} / 2014 / 230552 . \mathrm{htm}$. 
${ }^{68} \mathrm{ZMapp}^{\mathrm{TM}}$ (a collaboration between Mapp Biopharmaceutical, Inc., and LeafBio [San Diego, California], Defyrus Inc. [Toronto, Canada], the U.S. government, and the Public Health Agency of Canada [PHAC]), an experimental therapy to combat the Ebola virus, is a combination of monoclonal antibodies that has been demonstrated to treat rhesus macaques infected with the Ebola virus effectively. See, e.g., Qiu, X., et al. (2014). Reversion of advanced Ebola virus disease in nonhuman primates with ZMapp. Nature, 514(7520), 47-53; Kass, N. (2014). Ebola, ethics, and public health: What next? Annals of Internal Medicine, 161(10), 744-745; Pollack, A. (2014). Ebola drug could save a few lives. But whose? New York Times. Retrieved February 11, 2015 from http://www.nytimes.com/2014/08/09/health/in-ebola-outbreak-who-should-get-experimental-drug. html?_r=1; The White House. (2014). Fact Sheet: U.S. Response to the Ebola Epidemic in West Africa. Retrieved February 11, 2015 from http://www.whitehouse.gov/the-press-office/2014/09/16/fact-sheet-usresponse-ebola-epidemic-west-africa; World Health Organization (WHO). (2014). Ethical Considerations for Use of Unregistered Interventions for Ebola Viral Disease: Report of an Advisory Panel to WHO. Geneva, Switzerland: WHO. Retrieved February 11, 2015 from http://apps.who.int/iris/bitstream/10665/130997/1/ WHO_HIS_KER_GHE_14.1_eng.pdf?ua=1.

69 "Even though there may have been reason to give preference to foreign aid workers, the optics of giving scarce medicines to relatively well-off Caucasians proved damaging.... A decision to use experimental drugs on domestic workers might equally have provoked controversy, given the checkered history of Western pharmaceutical research in Africa." Gostin, L.O. (2014). Ethical allocation of drugs and vaccines in the West African Ebola epidemic. The Milbank Quarterly, 92(4), 664.

${ }^{70}$ Harvard School of Public Health. (2014a), supra note 1.

${ }^{71}$ Harvard School of Public Health. (2014b), supra note 1.

72 Rasmussen Reports. (2015, January 8). Americans are far less fearful of Ebola. Retrieved February 8, 2015 from http://www.rasmussenreports.com/public_content/lifestyle/general_lifestyle/january_2015/ americans_are_far_less_fearful_of_ebola.

73 Cass, C. (2014, October 5). Anxiety rising in U.S., but expert says Ebola outbreak 'extraordinarily unlikely'. Associated Press. Retrieved February 11, 2015 from http://www.pbs.org/newshour/rundown/anxiety-risingus-expert-says-ebola-outbreak-extraordinarily-unlikely/; Chevalier, M.S., et al. (2014). Ebola virus disease cluster in the United States: Dallas County, Texas, 2014. Morbidity and Mortality Weekly Report (MMWR), 63(46), 1087-1088; McCarty, C.L., et al. (2014). Response to importation of a case of Ebola virus disease: Ohio, October 2014. Morbidity and Mortality Weekly Report (MMWR), 63(46), 1089-1091.

${ }^{74}$ Frieden, T., Director, Centers for Disease Control and Prevention (CDC). (2014). Presentation to House Subcommittee on Africa, Global Health, Global Human Rights, and International Organizations. Retrieved February 12, 2015 from http://www.c-span.org/video/?c4506055/cdc-director-thomas-frieden-ebola-outbreak; Yasmin, S. (2014, September 30). Ebola's arrival in U.S. was inevitable, experts say. Dallas Morning News. Retrieved February 12, 2015 from http://www.dallasnews.com/news/metro/20140930-ebolas-arrival-in-u.s.was-inevitable-experts-say.ece.

75 Brilliant, L. (2014, October 17). Ebola: What should we do now? Wall Street Journal. Retrieved February 12, 2015 from http://www.wsj.com/articles/ebola-what-should-we-do-now-1413572275; Milbank, D. (2014, October 17). The nasty politicization of Ebola. Washington Post. Retrieved February 12, 2015 from http:// www.washingtonpost.com/opinions/dana-milbank-making-ebola-a-partisan-issue/2014/10/17/5322788855fd-11e4-892e-602188e70e9c_story.html; Shute, N. (2014, December 18). Is your state ready for the next infectious outbreak? Probably not. NPR. Retrieved February 12, 2015 from http://www.npr.org/blogs/ health/2014/12/18/371488523/is-your-state-ready-for-the-next-infectious-outbreak-probably-not; Tozzi, J., and B. Greeley (2014, October 14). Ebola tests America's weakened public health system. Bloomberg. Retrieved February 12, 2015 from http://www.businessweek.com/bw/articles/2014-10-14/ebola-a-weakenedu-dot-s-dot-public-health-system-readies-for-more-cases; Washington Post. (2014, August 17). Time to cut the hype and focus on the real dangers of Ebola. Washington Post. Retrieved February 12, 2015 from http://www.washingtonpost.com/opinions/time-to-cut-the-hype-and-focus-on-the-real-dangers-ofebola/2014/08/17/62ce7e64-2496-11e4-8593-da634b334390_story.html.

${ }^{76}$ Greenberg, J. (2014, October 19). George Will says a sneeze or cough could spread Ebola. Politifact.com. Retrieved February 17, 2015 from http://www.politifact.com/punditfact/statements/2014/oct/19/george-will/ george-will-claims-sneeze-cough-spread-ebola/. 
${ }_{77}$ Kupferschmidt, K. (2014, October 9). How to talk to the public about Ebola: Five tips from risk communication experts. ScienceInsider. Retrieved February 12, 2015 from http://news.sciencemag.org/ africa/2014/10/how-talk-public-about-ebola-five-tips-risk-communication-experts; Ratzan, S.C., and K.P. Moritsugu. (2014). Ebola crisis-Communication chaos we can avoid. Journal of Health Communication, 19(11), 1213-1215.

${ }_{78}$ Rosenbaum, L. (2015). Communicating uncertainty-Ebola, public health, and the scientific process. New England Journal of Medicine, 372(1), 7-9.

79 Burwell, S. (2014). Federal Government Response to Ebola. Senate Appropriations Committee Hearing [Video transcript], November 12. Retrieved February 12, 2015 from http://www.c-span.org/video/?322641-1/ hearing-federal-government-response-ebola.

${ }^{80}$ Rothstein, M.A., supra note 12.

${ }^{81}$ Gayle, H.D., President and CEO, CARE USA. (2015). Public Health Perspectives on the Current Ebola Epidemic in Western Africa. Presentation to the Bioethics Commission, February 5. Retrieved February 18, 2015 from http://bioethics.gov/node/4591; Bah, C., Youth Engagement Officer, A World at School; Chair, Youth Advocacy Group, Global Education First Initiative. (2015). How U.S. Public Attitudes and Policies Intended to Prevent Ebola in the United States Impact Affected Communities. Presentation to the Bioethics Commission, February 5. Retrieved February 18, 2015 from http://bioethics.gov/node/4592; Henwood, P.C., supra note 43

${ }^{82}$ Gostin, L.O., and E.A. Mok. (2009). Appendix E: Commissioned Paper. Global Health Governance Report. In The U.S. Commitment to Global Health: Recommendations for the Public and Private Sectors (pp. 203-246). Washington, DC: National Academies Press.

${ }^{83}$ Fink, S. (2014, September 3). Cuts at W.H.O. hurt response to Ebola crisis. New York Times. Retrieved February 11, 2015 from http://www.nytimes.com/2014/09/04/world/africa/cuts-at-who-hurt-response-to-ebolacrisis.html?_r=0; Gostin, L.O., and E.A. Mok, supra note 82; Lancet. (2014). WHO AFRO: In need of new leadership. Lancet, 384(9954), 1550; Oxfam. (2015). Improving International Governance for Global Health Emergencies: Lessons from the Ebola Crisis. Retrieved February 17, 2015 from http://www.oxfam.org/sites/ www.oxfam.org/files/file_attachments/dp-governance-global-health-emergencies-ebola-280115-en.pdf.

${ }^{84}$ Bevington, F., et al. (2015). Ebola as a case study: The role of local health departments in global health security. Journal of Public Health Management and Practice, 21(2), 220-223; Gostin, L.O., Hodge, J.G., and S. Burris. (2014). Is the United States prepared for Ebola? JAMA, 312(23), 2497-2498; U.S. Department of Health and Human Services. (2015, February 11). Commissioned Corps of the U.S. Public Health Service, America's Health Responders: Leadership. Retrieved February 19, 2015 from http://www.usphs.gov/aboutus/leadership. aspx; Update on the U.S. Public Health Response to the Ebola Outbreak: Hearing Before the H. Comm. On Oversight and Investigations, 114th Cong. (2014) (statement by Boris D. Lushniak, Acting Surgeon General of the United States).

${ }^{85}$ Glik, D.C. (2007). Risk communication for public health emergencies. Annual Review of Public Health, 28, 33-54; MacQueen, K.M., et al. (2001). What is community? An evidence-based definition for participatory public health. American Journal of Public Health, 91(12), 1929-1938.

${ }^{86}$ Covello, V.T. (2003). Best practices in public health risk and crisis communication. Journal of Health Communication, 8(S1), 5-8; Gayle, H.D., supra note 81.

87 Covello, V.T., supra note 86; Yasmin, S., supra note 46.

${ }^{88}$ Bradbury, J.A. (1989). The policy implications of differing concepts of risk. Science, Technology, \& Human Values, 14(4), 380-399; Moussaïd, M. (2013). Opinion formation and the collective dynamics of risk perception. PLoS ONE, 8(12), e84592; Petersen, A., and D. Lupton. (1996). The New Public Health: Health and Self in the Age of Risk. Thousand Oaks, CA: Sage Publications.

${ }^{89}$ Holmes, B.J. (2008). Communicating about emerging infectious disease: The importance of research. Health, Risk, \& Society, 10(4), 349-360.

90 Yasmin, S., supra note 46.

91 Ibid. 
92 Markel, H., supra note 7; Roberts, D.E., George A. Weiss University Professor of Law \& Sociology; Raymond Pace and Sadie Tanner Mossell Alexander Professor of Civil Rights; Director, Program on Race, Science, and Society, University of Pennsylvania. (2015). Historical, Sociological, and Legal Perspectives on U.S. Policies Intended to Prevent Ebola in the United States. Presentation to the Bioethics Commission, February 5. Retrieved February 18, 2015 from http://bioethics.gov/node/4593.

${ }_{93}$ Centers for Disease Control and Prevention (CDC). (2014). Quarantine and Isolation. Retrieved February 11, 2015 from http://www.cdc.gov/quarantine/.

${ }_{94}$ Centers for Disease Control and Prevention (CDC). (n.d.). Determining Risk of Ebola Transmission in Healthcare and Community settings. Retrieved February 11, 2015 from http://www.cdc.gov/vhf/ebola/hcp/ international/determining-risk.html.

${ }^{5}$ Courage, K.H. (2014, October 24). Inside the 4 U.S. Biocontainment Hospitals That Are Stopping Ebola. Scientific American. Retrieved February 11, 2015 from http://www.scientificamerican.com/article/inside-the4-u-s-biocontainment-hospitals-that-are-stopping-ebola-video/; Neuman, S. (2014, October 6). Why Ebola patients are getting treatment in Nebraska. NPR. Retrieved February 11, 2015 from http:/www.npr.org/blogs/ thetwo-way/2014/10/06/354083214/why-ebola-patients-are-getting-treatment-in-nebraska.

${ }_{96}$ Centers for Disease Control and Prevention (CDC). (2014). For General Healthcare Settings in West Africa: Four Keys to Infection Control. Retrieved February 11, 2015 from http://www.cdc.gov/vhf/ebola/hcp/ international/keys-to-infection-control.html.

${ }_{97}$ Centers for Disease Control and Prevention (CDC), supra note 93.

${ }_{98}$ Cetron, M., and J. Landwirth. (2005). Public health and ethical considerations in planning for quarantine. Yale Journal of Biology and Medicine, 78(5), 325-330.

99 Pengelly, M. (2014, November 17). Kaci Hickox accuses governors of exploiting Ebola fears for political gain. The Guardian. Retrieved February 13, 2015 from http://www.theguardian.com/world/2014/nov/17/ kaci-hickox-ebola-accuses-chris-christe-paul-lepage.

${ }^{100}$ Phillip, A. (2014, October 4). Why hasn't the U.S. closed its airports to travelers from Ebola-ravaged countries? Washington Post. Retrieved February 11, 2015 from http://www.washingtonpost.com/news/to-your-health/ wp/2014/10/01/why-hasnt-the-u-s-closed-its-airports-to-travelers-from-ebola-ravaged-countries/; Taylor, A. (2014, November 6). Why are Australia and Canada following North Korea's lead on Ebola? Washington Post. Retrieved February 11, 2015 from http://www.washingtonpost.com/blogs/worldviews/wp/2014/11/06/ why-are-australia-and-canada-following-north-koreas-lead-on-ebola/.

${ }^{101}$ Centers for Disease Control and Prevention (CDC). (2015). Interim U.S. Guidance for Monitoring and Movement of Persons with Potential Ebola Virus Exposure. Retrieved February 11, 2015 from http://www.cdc. gov/vhf/ebola/exposure/monitoring-and-movement-of-persons-with-exposure.html.

102 Ibid.

${ }^{103}$ U.S. Constitution Amendment X ("The powers not delegated to the United States by the Constitution, nor prohibited by it to the states, are reserved to the states respectively, or to the people”); U.S. Const. Art. 1, $\$ 8$, cl. 3 (stating that Congress has the power to "regulate commerce with foreign nations, and among the several states and with the Indian tribes”); Regulations to Control Communicable Diseases, 42 U.S.C. \$264(a).

${ }^{104}$ U.S. Constitution Amendment V (the Fifth Amendment is applicable to the federal government); U.S. Constitution Amendment XIV, $\$ 1$ (the Fifth Amendment's provisions apply to the states through the Due Process Clause of the Fourteenth Amendment).

${ }^{105}$ Daubert, M.A. (2007). Pandemic fears and contemporary quarantine: Protecting liberty through a continuum of due process rights. Buffalo Law Review, 54, 1299-1353, p. 1310.

${ }^{106}$ Ibid, pp. 1316-1317 (citing Goldberg v. Kelly, 397 U.S. 254, 267-68 [1970]).

${ }^{107}$ Upshur, R.E.G. (2002). Principles for the justification of public health intervention. Canadian Journal of Public Health, 93(2), 101-103.

${ }^{108}$ Mill, J.S. (2003). On Liberty. D. Bromwich and G. Kateb. (Eds.). New Haven, CT: Yale University Press, p. 80; Feinberg, J. (1984). The Moral Limits of Criminal Law: Harm to Others. New York, NY: Oxford University Press. 
${ }^{109}$ Baum, N.M., et al. (2007). Looking ahead: Addressing ethical challenges in public health practice. Journal of Law, Medicine \& Ethics, 35(4), 657-667; Rychetnik, L., et al. (2004). A glossary for evidence based public health. Journal of Epidemiology and Community Health, 58(7), 538-545; Victora, C.G., Habicht, J.P., and J. Bryce. (2004). Evidence-based public health: Moving beyond randomized trials. American Journal of Public Health, 94(3), 400-405.

${ }^{110}$ Childress, J.F., et al. (2002). Public health ethics: Mapping the terrain. Journal of Law, Medicine \& Ethics, 30(2), 170-178; Feinberg, J., supra note 108; Jennings, B., and J. Arras. (2015, forthcoming). Ethical Aspects of Public Health Emergency Preparedness and Response. In B. Jennings, et al. (Eds.). Emergency Ethics: Public Health Preparedness and Response. New York, NY: Oxford University Press.

${ }^{111}$ Childress, J.F., et al., supra note 110.

${ }^{112}$ Upshur, R.E.G., et al. (2007). Ethics in an epidemic: Ethical considerations in preparedness planning for pandemic influenza. Health Law Review, 16(1), 33-39.

${ }^{113}$ Gostin, L.O., Bayer, R., and A.L. Fairchild. (2003). Ethical and legal challenges posed by severe acute respiratory syndrome: Implications for the control of severe infectious disease threats. $J A M A, 290(24)$, 3229-3237.

${ }^{114}$ American Academy of Pediatrics. (2015, February 6). Comments submitted to the Bioethics Commission.

${ }^{115}$ Kass, N.E. (2001). An ethics framework for public health. American Journal of Public Health, 91(11), 1776-1782.

116 Bestman-Yates, O., President, Staten Island Liberian Community Association (SILCA). (2015). How U.S. Public Attitudes and Policies Intended to Prevent Ebola in the United States Impact Affected Communities. Presentation to the Bioethics Commission, February 5. Retrieved February 18, 2015 from http://bioethics. gov/node/4592; Kozlowska, H. (2014, October 21). Has Ebola exposed a strain of racism? New York Times. Retrieved February 11, 2015 from http://op-talk.blogs.nytimes.com/2014/10/21/has-ebola-exposed-a-strain-ofracism/; Roberts, D.E., supra note 92.

${ }^{117}$ Bayer, R., and J. Stuber. (2006). Tobacco control, stigma, and public health: Rethinking the relations. American Journal of Public Health, 96(1), 47-50; Corrigan, P. (2004). How stigma interferes with mental health care. American Psychologist, 59(7), 617-625; Florom-Smith, A.L., and J.P. De Santis. (2012). Exploring the concept of HIV-related stigma. Nursing Forum, 47(3), 153-165; Goffman, E. (1963). Stigma: Notes on the Management of Spoiled Identity. London, UK: Penguin Group; Puhl, R.M., and C.A. Heuer. (2010). Obesity stigma: Important considerations for public health. American Journal of Public Health, 100(6), 1019-1028.

${ }^{118}$ Hatzenbuehler, M.L., Phelan, J.C., and B.G. Link. (2013). Stigma as a fundamental cause of population health inequalities. American Journal of Public Health, 103(5), 813-821; World Health Organization (WHO). (2003). Social Determinants of Health: The Solid Facts, Second Edition. R. Wilkinson and M. Marmot. (Eds.). Copenhagen, Denmark: World Health Organization.

${ }^{119}$ Haglage, A. (2014, October 15). Ebola racism reaches a new low in Texas. The Daily Beast. Retrieved February 11, 2015 from http://www.thedailybeast.com/articles/2014/10/15/texas-college-s-ebola-racism-reaches-anew-low.html.

${ }^{120}$ Hagan, E. (2014, October 27). 'My name is not Ebola': African children bullied at school. New York Post. Retrieved February 11, 2015 from http://nypost.com/2014/10/27/my-name-is-not-ebola-african-childrenbullied-at-school/.

${ }^{121}$ AllAfrica. (2014, October 6). Liberia: Health workers battling Ebola stigma in Ebola-stricken Liberia. Retrieved February 11, 2015 from: http://allafrica.com/stories/201410060668.html; Henwood, P.C., supra note 43; McCoy, T., (2014, September 19). Why the brutal murder of several Ebola workers may hint at more violence to come. Retrieved February 11, 2015 from http:/www.washingtonpost.com/news/morning-mix/ wp/2014/09/19/why-the-brutal-murder-of-eight-ebola-workers-may-hint-at-more-violence-to-come/; Szabo, L. (2014, November 5). Louisiana bars Ebola researchers from conference. USA Today. Retrieved February 11, 2015 from http://www.usatoday.com/story/news/nation/2014/11/05/ebola-doctor-meeting/18526831/; Wilson, J. (2014, September 19). 8 killed in Guinea town over Ebola fears. Retrieved February 11, 2015 from http://www. cnn.com/2014/09/19/health/ebola-guinea-killing/.

${ }^{122}$ Hartocollis, A., and N. Schweber. (2014, October 29). Bellevue employees face Ebola at work, and stigma of it everywhere. New York Times. Retrieved February 11, 2015 from http://www.nytimes.com/2014/10/30/ nyregion/bellevue-workers-worn-out-from-treating-ebola-patient-face-stigma-outside-hospital.html. 
${ }^{123}$ Jacobson, R. (2014, November 12). Ebola relief is stymied by unnecessary restrictions on health workers. Scientific American. Retrieved February 11, 2015 from http://www.scientificamerican.com/article/ ebola-relief-is-stymied-by-unnecessary-restrictions-on-health-workers/.

${ }^{124}$ Belluz, J., and S. Hoffman. (2014, October 18). The evidence on travel bans for diseases like Ebola is clear: They don't work. Vox; Bristol, N. (2009). USA looks set to repeal HIV travel ban. Lancet, 374(9699), 1409; Preston, J. (2009, October 30). Obama lifts a ban on entry into U.S. by H.I.V.-positive people. New York Times. Retrieved February 12, 2015 from http://www.nytimes.com/2009/10/31/us/politics/31travel.html?_r=0.

${ }^{125}$ Obama, B. (2009, October 30). Remarks by the President at signing of the Ryan White HIV/AIDS Treatment Extension Act of 2009. Retrieved February 12, 2015 from http://www.whitehouse.gov/the-press-office/ remarks-president-signing-ryan-white-hivaids-treatment-extension-act-2009.

${ }^{126}$ Gonsalves, G., and P. Staley. (2014). Panic, paranoia, and public health-The AIDS epidemic's lessons for Ebola. New England Journal of Medicine, 371(25), 2348-2349, p. 2349.

${ }^{127}$ Zaki, A.M., et al. (2012). Isolation of a novel coronavirus from a man with pneumonia in Saudi Arabia. New England Journal of Medicine, 367(19), 1814-1820.

${ }^{128}$ Muller, M.P., and A. McGeer. (2007). Severe acute respiratory syndrome (SARS) coronavirus. Seminars in Respiratory and Critical Care Medicine, 28(2), 201-212.

${ }^{129}$ Centers for Disease Control and Prevention (CDC). (2003). Efficiency of quarantine during an epidemic of severe acute respiratory syndrome-Beijing, China, 2003. Morbidity and Mortality Weekly Report (MMWR), 52(43), 1037-1040; Schabas, R. (2004). Severe acute respiratory syndrome: Did quarantine help? Canadian Journal of Infectious Diseases \& Medical Microbiology, 15(4), 204; Centers for Disease Control and Prevention (CDC). (2003). Update: Outbreak of severe acute respiratory syndrome-worldwide, 2003. Morbidity and Mortality Weekly Report (MMWR), 52(13), 269-272; Svoboda, T., et al. (2004). Public health measures to control the spread of the severe acute respiratory syndrome during the outbreak in Toronto. New England Journal of Medicine, 350(23), 2352-2361.

${ }^{130}$ Central Intelligence Agency. (2014). The World Factbook: Singapore. Retrieved February 12, 2015 from https:// www.cia.gov/library/publications/the-world-factbook/geos/sn.html; Micklethwait, J., and A. Woolridge. (2014). The state of the state: The global contest for the future of government. Foreign Affairs. Retrieved February 12, 2015 from http://www.foreignaffairs.com/articles/141477/john-micklethwait-and-adrian-wooldridge/the-stateof-the-state; Ortmann, S. (2014). Democratization and the discourse on stability in Hong Kong and Singapore. Taiwan Journal of Democracy, 10(1), 123-145, p. 124.

${ }^{131}$ James, L., et al. (2006). Public health measures implemented during the SARS outbreak in Singapore, 2003. Public Health, 120(1), 20-26; Ooi, P.L., Lim, S., and S.K. Chew. (2005). Use of quarantine in the control of SARS in Singapore. American Journal of Infection Control, 33(5), 252-257.

132 Ibid.

${ }^{133}$ Gostin, L.O., Bayer, R., and A.L. Fairchild, supra note 113.

${ }^{134}$ Ooi, P.L., Lim, S., and S.K. Chew, supra note 131.

${ }^{135}$ Ries, N.M. (2004). Public health law and ethics: Lessons from SARS and quarantine. Health Law Review, 13(1), 3-6; Schabas, R., supra note 129; Svoboda, T., et al., supra note 129.

${ }^{136}$ Schabas, R., supra note 129, at 204; Dwosh, H.A., et al. (2003). Identification and containment of an outbreak of SARS in a community hospital. Canadian Medical Association Journal, 168(11), 1415-1420.

${ }^{137}$ Ali, S.H. (2008). Stigmatized ethnicity, public health, and globalization. Canadian Ethnic Studies, 40(3), 43-64; Pearson, B., et al. (2004). Fear and stigma: The epidemic within the SARS outbreak. Emerging Infectious Diseases, 10(2), 358-363; Wallis, P., and B. Nerlich. (2005). Disease metaphors in new epidemics: The UK media framing of the 2003 SARS epidemic. Social Science \& Medicine, 60, 2629-2639.

${ }^{138}$ Pearson, B., et al., supra note 137. 
${ }^{139}$ Centers for Disease Control and Prevention (CDC). (2014). Tuberculosis. [Webpage]. Retrieved February 12, 2015 from http://www.cdc.gov/tb/default.htm; National Institute of Allergy and Infectious Diseases. (2014). Tuberculosis (TB) [Webpage]. Retrieved February 12, 2015 from http://www.niaid.nih.gov/topics/tuberculosis/ understanding/pages/default.aspx; World Health Organization (WHO). (2013). Global Tuberculosis Report 2013. Retrieved February 12, 2015 from http://apps.who.int/iris/bitstream/10665/91355/1/9789241564656_ eng.pdf.

${ }^{140}$ Centers for Disease Control and Prevention (CDC). (2014). Legal Authorities for Isolation and Quarantine [Webpage]. Retrieved February 12, 2015 from http://www.cdc.gov/quarantine/ aboutLawsRegulationsQuarantineIsolation.html.

${ }^{141}$ National Conference of State Legislatures. (2014). State Quarantine and Isolation Statutes. Retrieved February 12, 2015 from http://www.ncsl.org/research/health/state-quarantine-and-isolation-statutes.aspx.

${ }^{142}$ See generally, Gutmann, A., and D. Thompson, supra note 23; Gutmann, A., and D. Thompson. (1997). Deliberating about bioethics. Hastings Center Report, 27(3), 38-41.

${ }^{143}$ Centers for Disease Control and Prevention (CDC). (2014). Mission, Role and Pledge [Webpage]. Retrieved February 12, 2015 from http://www.cdc.gov/about/organization/mission.htm.

${ }^{144}$ Effectiveness is defined as "a measure of the extent to which a specific intervention, procedure, regimen, or service, when deployed in the field in usual circumstances, does what it is intended to do for a specified population." Efficacy is defined as "[t]he extent to which a specific intervention, procedure, regimen, or service produces a beneficial result under ideal conditions." See Porta, M. (Ed.). (2008). A Dictionary of Epidemiology, Fifth Edition. New York, NY: Oxford University Press.

${ }^{145}$ Médecins Sans Frontières. (2014, December 26). Clinical trial for potential Ebola treatment started in MSF clinic in Guinea. Retrieved February 12, 2015 from http://www.msf.org/article/clinical-trial-potential-ebolatreatment-started-msf-clinic-guinea; ClinicalTrials.gov. (2014). A Study to Find Out if the New Ebola Vaccine is Safe and Stimulated Immunity That Might Protect Adults in Kilifi, Kenya. Retrieved February 12, 2015 from http://clinicaltrials.gov/ct2/show/NCT02296983.

${ }^{146}$ Boyko, E.J. (2013). Observational research opportunities and limitations. Journal of Diabetes Complications, 27(6), 642-648; Cartwright, N. (2011). The art of medicine: A philosopher's view of the long road from RCTs to effectiveness. Lancet, 377(9775), 1400-1401.

${ }^{147}$ Akobeng, A.K. (2005). Understanding randomised controlled trials. Archives of Disease in Childhood, 90(8), 840-844.

${ }^{148}$ Cox, E., Borio, L., and R. Temple. (2014). Evaluating Ebola therapies-the case for RCTs. New England Journal of Medicine, 371(25), 2350-2351; Borio, L., Assistant Commissioner for Counterterrorism Policy; Director, Office of Counterterrorism and Emerging Threats, U.S. Food and Drug Administration (FDA). (2015). Ethical Issues Associated with Research in the Context of a Public Health Emergency. Presentation to the Bioethics Commission, February 5. Retrieved February 18, 2015 from http://bioethics.gov/node/4590.

${ }^{149}$ Confounding occurs when a third factor that is correlated with both the explanatory and response variable influences the observed effect of the variable under investigation, but is not causally in between the explanatory variable and the response variable. Effect modification occurs when the magnitude of the observed effect of the variable under investigation differs depending on a third factor. Greenland, S., and H. Morgenstern. (1989). Ecological bias, confounding, and effect modification. International Journal of Epidemiology, 18(1), 269-274; U.S. Food and Drug Administration (FDA). (2010, February). Guidance for Industry: Adaptive Design Clinical Trials for Drugs and Biologics (Draft Guidance). Retrieved February 12, 2015 from http://www.fda. gov/downloads/Drugs/Guidances/ucm201790.pdf

${ }^{150}$ Cox, E., Borio, L., and R. Temple, supra note 148; Goodman, J.L. (2014). Studying "secret serums"-Toward safe, effective Ebola treatments. New England Journal of Medicine, 371(12), 1086-1089; Joffe, S. (2014). Evaluating novel therapies during the Ebola epidemic. JAMA, 312(13), 1299-1300; Moses, L. (2014, December 1). Don't ignore established research ethics when treating Ebola. New York Times. Retrieved February 12, 2015 from http://www.nytimes.com/roomfordebate/2014/12/01/experimental-drugs-and-the-ethics-of-fightingebola/dont-ignore-established-research-ethics-when-treating-ebola. 
${ }^{151}$ Chiodo, G.T., Tolle, S.W., and L. Bevan. (2000). Placebo controlled trials: Good science or medical neglect? Western Journal of Medicine, 172(4), 271-273.

${ }^{152}$ Cox, E., Borio, L., and R. Temple, supra note 148.

${ }^{153}$ Rid, A., and E.J. Emanuel. (2014). Ethical considerations of experimental interventions in the Ebola outbreak. Lancet, 384(9957), 1896-1899.

${ }^{154}$ Presidential Commission for the Study of Bioethical Issues (PCSBI). (2011, December). Moral Science: Protecting Participants in Human Subjects Research. Washington, DC: PCSBI, p. 90.

${ }^{155}$ Cox, E., Borio, L., and R. Temple, supra note 148; Goodman, J.L., supra note 150; Joffe, S., supra note 150.

${ }^{156}$ Ibid; Joffe, S., supra note 150.

${ }^{157}$ European Centre for Disease Prevention and Control, supra note 57; Focosi, D., and F. Maggi, supra note 55.

${ }^{158}$ Adebamowo, C.A., et al. (2014). Randomised controlled trials for Ebola: Practical and ethical issues. Lancet, 384(9952), 1423-1424.

${ }^{159}$ Cohen, J., and K. Kupferschmidt. (2014). Ebola vaccine trials raise ethical issues. Science, 346(6207), $289-290$.

${ }^{160}$ Edwards, S.J. (2013). Ethics of clinical science in a public health emergency: Drug discovery at the bedside. American Journal of Bioethics, 13(9), 3-14.

${ }^{161}$ University of Oxford. (2014, November 13). Oxford to lead trial of experimental drug in Ebola patients. Retrieved February 12, 2015 from http://www.ox.ac.uk/news/2014-11-13-oxford-lead-trial-experimentaldrug-ebola-patients.

${ }^{162}$ U.S. Food and Drug Administration (FDA), supra note 149; Chow, C. (2014). Adaptive clinical trial design. Annual Review of Medicine, 65, 405-415; Brown, C.H., et al. (2009). Adaptive designs for randomized trials in public health. Annual Review of Public Health, 30, 1-25; Kass, N., and S. Goodman. (2014, December 1). Trials tempered by compassion and humility. New York Times. Retrieved February 12, 2015 from http:// www.nytimes.com/roomfordebate/2014/12/01/experimental-drugs-and-the-ethics-of-fighting-ebola/ trials-tempered-by-compassion-and-humility.

${ }^{163}$ PCSBI, supra note 154.

${ }^{164}$ London, A.J. (2015, forthcoming). Research in a Public Health Crisis: The Integrative Approach to Managing the Moral Tensions. In B. Jennings, et al. (Eds.). Emergency Ethics: Public Health Preparedness and Response. New York, NY: Oxford University Press.

${ }^{165}$ Emanuel, E.J., Wendler, D., and C. Grady. (2000). What makes clinical research ethical? JAMA, 283(20), 2701-2711.

${ }^{166}$ PCSBI, supra note 154 , at 88.

${ }^{167}$ Kant, I. (1996). Groundwork of the Metaphysics of Morals. In M.J. Gregor. (Ed.). The Cambridge Edition of the Works of Immanuel Kant: Practical Philosophy. Cambridge, UK: Cambridge University Press.

${ }^{168}$ Jonsen, A.R., and F.G. Miller. (2008). Research with healthy volunteers. In E.J. Emanuel, et al. (Eds.). The Oxford Textbook of Clinical Research Ethics (pp. 481-487). New York, NY: Oxford University Press.

${ }^{169}$ Gray, G.E., et al. (2014). Recombinant adenovirus type 5 HIV gag/pol/nef vaccine in South Africa: Unblinded, long-term follow-up of the phase 2b HVTN 503/Phambili study. Lancet Infectious Diseases, 14(5), 388-396; Buchbinder, S.P., et al. (2008). Efficacy assessment of a cell-mediated immunity HIV-1 vaccine (the Step Study): A double-blind, randomised, placebo-controlled, test-of-concept trial. Lancet, 372(9653), 1881-1893.

${ }^{170}$ PCSBI, supra note 154 , at 92.

${ }^{171}$ Borio, L., supra note 148.

172 Adebamowo, C.A, Professor, Epidemiology and Public Health, Department of Epidemiology and Public Health, Institute of Human Virology, and Greenebaum Cancer Center, University of Maryland School of Medicine. (2015). Ethical Issues Associated with Research in the Context of a Public Health Emergency. Presentation to the Bioethics Commission, February 5. Retrieved February 18, 2015 from http://bioethics.gov/ node/4590. 
${ }^{173}$ Boyles, T. (2014). Priorities in Ebola research: A view from the field. Lancet, 385(9962), 23; Roberts, I., and A. Perner. (2014). Ebola virus disease: Clinical care and patient centered research. Lancet, 384(9959), 2001-2002.

${ }^{174}$ PCSBI, supra note 154 , at 85-86.

${ }^{175}$ Adebamowo, C.A, et al., supra note 158; Kanapathipillai, R., et al. (2014). Ebola vaccine: An urgent international priority. New England Journal of Medicine, 371(24), 2249-2251; Toure, A. (2014, December 3). People infected with Ebola would fear a placebo. New York Times. Retrieved February 12, 2015 from http:/www.nytimes.com/roomfordebate/2014/12/01/experimental-drugs-and-the-ethics-of-fighting-ebola/ people-infected-with-ebola-would-want-more-than-a-50-percent-chance; Ebola Response Anthropology Platform, Working Group on Clinical Trials. (2014). Anthropology and Ebola clinical trials: Working group working document. Retrieved February 16, 2015 from http://www.ebola-anthropology.net/key_messages/ anthropology-ebola-clinical-research/.

${ }^{176}$ Cohen, J., and K. Kupferschmidt, supra note 159.

${ }^{177}$ PCSBI, supra note 154, at 93.

${ }_{178}$ Olliaro, P., et al. (2015, February 2). Ethical issues with the conduct of treatment trials for Ebola virus disease in endemic settings. Comments submitted to the Bioethics Commission.

${ }^{179}$ World Health Organization (WHO). (2014). Ethical issues related to study design for trials on therapeutics for Ebola virus disease. (WHO Reference No. WHO/HIS/KER/GHE/14.2). Retrieved February 12, 2015 from http://www.who.int/csr/resources/publications/ebola/ethical-evd-therapeutics/en/.

${ }^{180}$ Kass, N., and S. Goodman, supra note 162.

${ }^{181}$ U.S. Food and Drug Administration (FDA), supra note 149; Chow, C., supra note 162; Brown, C.H., et al., supra note 162.

${ }^{182}$ Schwartz, J.L. (2014, December 2). Creative and time-efficient approaches to curbing Ebola are necessary. New York Times. Retrieved February 12, 2015, from http://www.nytimes.com/roomfordebate/2014/12/01/ experimental-drugs-and-the-ethics-of-fighting-ebola/creative-and-time-efficient-approaches-to-curbingebola-are-necessary.

${ }^{183}$ Chertow, D.S., et al. (2014). Ebola virus disease in West Africa: Clinical manifestations and management. New England Journal of Medicine, 371(22), 2054-2057; Disease Surveillance and Response Programme Area-Disease Prevention and Control Cluster, World Health Organization (WHO). (2014). Contact Tracing During an Outbreak of Ebola Virus Disease. Brazzaville, Congo: World Health Organization Regional Office for Africa. Retrieved February 12, 2015 from http://www.who.int/csr/resources/publications/ebola/contact-tracing-duringoutbreak-of-ebola.pdf; Feldmann, H., and T.W. Geisbert. (2011). Ebola haemorrhagic fever. Lancet, 377(9768), 849-862.

${ }^{184}$ London, A.J., supra note 164.

${ }^{185}$ Mascalzoni, D., et al. (2014). International Charter of principles for sharing bio-specimens and data. European Journal of Human Genetics, 1-8; Upshur, R.E.G., Lavery, J.V., and P.O. Tindana. (2007). Taking tissue seriously means taking communities seriously. BMC Medical Ethics, 8, 11-16.

${ }^{186}$ Burnouf, T., and J. Seghatchian. (2014). Ebola virus convalescent blood products: Where we are now and where we may need to go. Transfusion and Apheresis Science, 51(2014), 120-125; Institute of Tropical Medicine Antwerp (2014, October 13). Blood of Ebola survivors tested as short-term treatment option. Retrieved February 10, 2015 from http://www.sciencedaily.com/releases/2014/10/141023091819.htm; Morin, M. (2014, November 19). Ebola: Gates Foundation funds convalescent plasma research. Los Angeles Times. Retrieved February 12, 2015 from http://latimes.com/science/sciencenow/la-sci-sn-ebola-gates-celebrity-20141119story.html; Bill and Melinda Gates Foundation. (2014, November 18). Gates Foundation Announces support to Ebola-Affected Countries to Accelerate the Evaluation of Potential Treatments [Press Release]. Retrieved February 12, 2015 from http:/www.gatesfoundation.org/Media-Center/Press-Releases/2014/11/ Support-to-Ebola-Affected-Countries-Announcement.

${ }^{187}$ Steenhuysen, J. (2014, November 5). U.S. Ebola researchers plead for access to virus samples. Reuters. Retrieved February 10, 2015 from http://news.yahoo.com/exclusive-u-ebola-researchers-plead-access-virus-samples120335606--finance.html. 
${ }^{188}$ Mascalzoni, D., et al., supra note 185.

${ }^{189}$ Beauchamp, T.L., and J.F. Childress. (2012). Principles of Biomedical Ethics, Seventh Edition. Oxford, UK: Oxford University Press; National Commission for the Protection of Human Subjects of Biomedical and Behavioral Research. (1978). The Belmont Report: Ethical Principles and Guidelines for the Protection of Human Subjects of Research (DHEW Publication OS 78-0012). Washington, DC: Department of Health, Education, and Welfare. Retrieved February 10, 2015 from http://www.hhs.gov/ohrp/humansubjects/guidance/belmont. html.

${ }^{190}$ Calain, P., et al. (2009). Research ethics and international epidemic response: The case of Ebola and Marburg hemorrhagic fevers. Public Health Ethics, 2(1), 7-29.

${ }^{191}$ Mascalzoni, D., et al., supra note 185 , at 2.

${ }^{192}$ Presidential Commission for the Study of Bioethical Issues (PCSBI). (2012, October). Privacy and Progress in Whole Genome Sequencing. Washington, DC: PCSBI, pp. 91-92.

${ }^{193}$ Protection of Human Subjects, HHS. 45 C.F.R. $\$ 46.102(f)$.

${ }^{194}$ McGuire, A.L., et al. (2010). Taking DNA from the dead. Nature Reviews Genetics, 11(5), 318.

195 Protection of Human Subjects, HHS. 45 C.F.R. $\$ 46.101(\mathrm{~b})(4)$.

${ }^{196}$ Mascalzoni, D., et al., supra note 185; Upshur, R.E.G., Lavery, J.V., and P.O. Tindana, supra note 185.

${ }^{197}$ Kolata, G. (2014, December 1). The virus detectives: Sifting through genes in search of answers on Ebola. New York Times, p. D1.

198 Ibid.

${ }^{199}$ Rothstein, M.A. (2010). Is deidentification sufficient to protect health privacy in research? American Journal of Bioethics, 10(9), 3-11.

${ }^{200}$ Sweeney, L., Abu, A., and J. Winn. (2013). Identifying participants in the personal genome project by name. Data Privacy Lab, Harvard University. Retrieved February 12, 2015 from http://privacytools.seas.harvard.edu/ publications/identifying-participants-personal-genome-project-name; Lin, Z., Owen, A.B., and R.B. Altman. (2004). Genomic research and human subject privacy. Science, 305(5681), 183; Gymrek, M., et al. (2013). Identifying personal genomes by surname inference. Science, 339(6117), 321-324.

${ }^{201}$ Walker, R.L., et al. (2014). Genomic research with the newly dead: A crossroads for ethics and policy. Journal of Law, Medicine \& Ethics, 42(2), 220-231.

${ }^{202}$ PCSBI, supra note 192 , at 81-82.

${ }^{203}$ National Institutes of Health (NIH). (2014). National Institutes of Health Genomic Data Sharing Policy. Retrieved February 11, 2015 from http://gds.nih.gov/PDF/NIH_GDS_Policy.pdf.

${ }^{204}$ Ibid.

${ }^{205}$ Ibid.

${ }^{206}$ Mascalzoni, D., et al., supra note 185.

${ }^{207}$ Elbe, S. (2010). Haggling over viruses: The downside risks of securitizing infectious disease. Health Policy and Planning, 25(6), 476-485.

${ }^{208}$ Ibid, at 477 .

${ }^{209}$ Elbe, S., supra note 207; Fidler, D.P. (2008). Influenza virus samples, international law, and global health diplomacy. Emerging Infectious Diseases, 14(1), 88-94. The Indonesian government's position was based, in part, on Article 15 of the Convention on Biological Diversity, which affirms the sovereign right of nations to the genetic resources within their territories and fair and equitable access to benefits arising out of research and commercial use from these resources. Zhang, X. (2010). Attitudes towards transfers of human tissue samples across borders: An international survey of researchers and policy makers in five countries. BMC Medical Ethics, $11,16$. 
${ }^{210}$ Fidler, D.P. (2010). Negotiating equitable access to influenza vaccines: Global health diplomacy and the controversies surrounding avian influenza $\mathrm{H} 5 \mathrm{~N} 1$ and pandemic influenza H1N1. PLoS Medicine, 7(5), e1000247.

${ }^{211}$ Ibid, at 2 .

${ }^{212}$ Fidler, D.P., supra note 210.

${ }^{213}$ Gostin, L.O., et al. (2014). Virus sharing, genetic sequencing, and global health security. Science, 345(6202), 1295-1296.

${ }^{214} \mathrm{Ibid}$, at 1295 .

215 Ibid.

${ }^{216}$ PCSBI, supra note 24, pp. 24-25, 113.

${ }^{217}$ Government Accountability Office (GAO). (2007, October 4). High-Containment Biosafety Laboratories: Preliminary Observations of the Oversight of the Proliferation of BSL-3 and BSL-4 Laboratories in the United States. Statement of Keith Rhodes.

${ }^{218}$ Ibid; Pappalardo, J. (2009, April 27). Virus hunters: Inside Maryland's Biosafety Level 4 Lab. Popular Mechanics. Retrieved February 11, 2015 from http://www.popularmechanics.com/science/health/a6369/4315093/.

${ }^{219}$ Tindana, P., et al. (2014). Ethical issues in the export, storage, and reuse of human biological samples in biomedical research: Perspectives of key stakeholders in Ghana and Kenya. BMC Medical Ethics, 15, 76.

${ }^{220}$ Steenhuysen, J., supra note 187.

${ }^{221}$ Ibid.

${ }^{222}$ Upshur, R.E.G., Lavery, J.V., and P.O. Tindana, supra note 185.

${ }^{223}$ Presidential Commission for the Study of Bioethical Issues (PCSBI). (2011, September). Research Across Borders: Proceedings of the International Research Panel of the Presidential Commission for the Study of Bioethical Issues. Washington, DC: PCSBI, p. 10.

${ }^{224}$ Ibid.

${ }^{225}$ European Union, Directive 95/46/EC (1995); National Institutes of Health (NIH), supra note 203; HIPAA Privacy Rule, 45 C.F.R. $\$ 160,164$.

${ }^{226}$ PCSBI, supra note 192 , at 81-82.

${ }^{227}$ Mascalzoni, D., et al., supra note 185.

${ }^{228}$ Calain, P., et al, supra note 190.

${ }^{229}$ Mascalzoni, D., et al., supra note 185; Tindana, P., et al., supra note 219; Upshur, R.E.G., Lavery, J.V., and P.O. Tindana, supra note 185; Zhang, X., supra note 209.

${ }^{230}$ Gutmann, A., and D.F. Thompson. (2010). Deliberative Democracy. In R.A. Couto. (Ed.). Political and Civic Leadership: A Reference Handbook (pp. 325-332). Washington, DC: Sage Publications, Inc., p. 328. 
APPENDICES 
Appendix I: Map of Countries Most Affected by 2014-2015 Ebola Epidemic

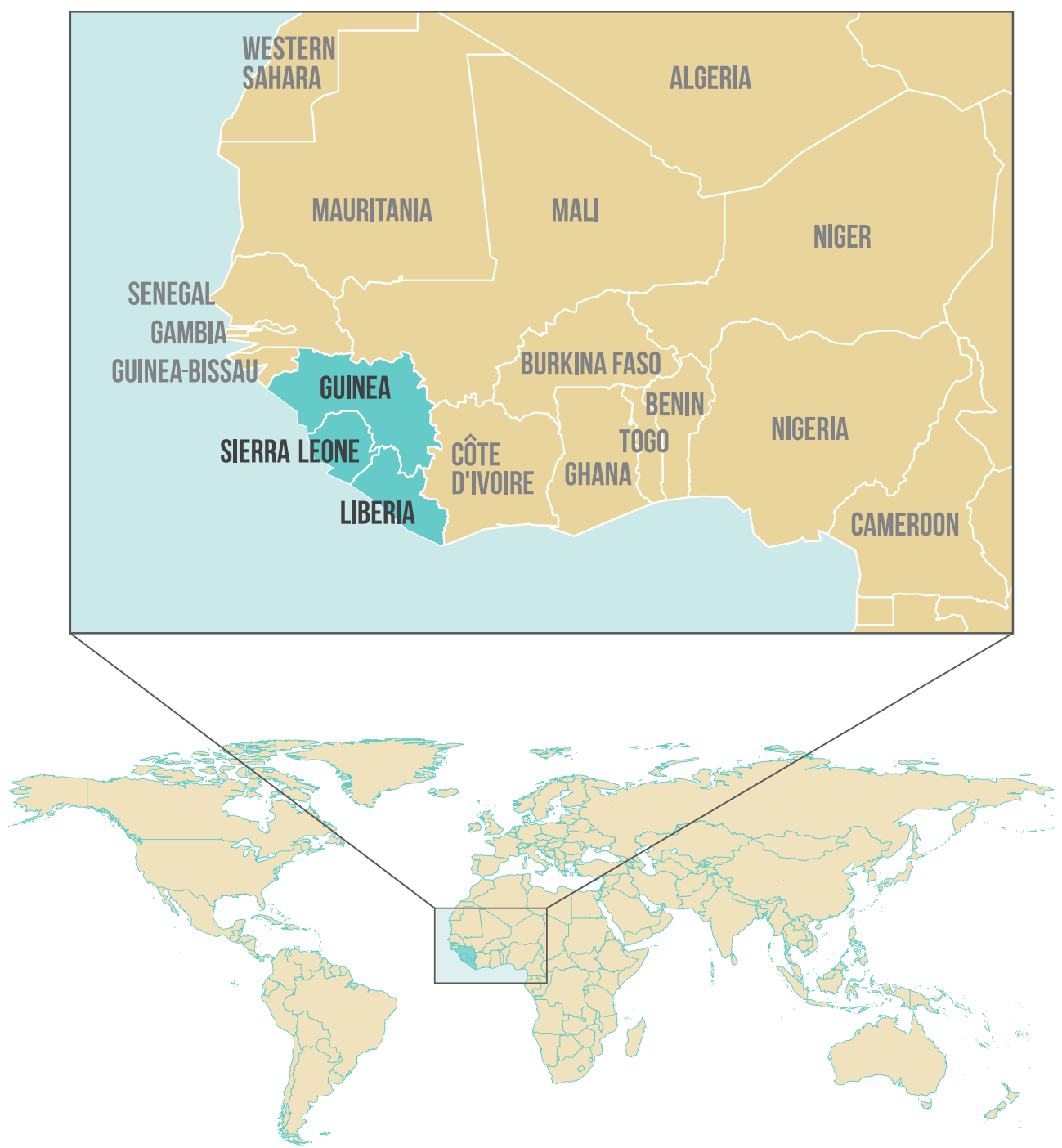




\section{Appendix II: Guest Presenters to the Bioethics Commission Regarding Ethics, Public Health Emergency Preparedness and Response, and the Ebola Epidemic}

Clement A. Adebamowo, B.M., Ch.B., F.W.A.C.S., F.A.C.S., Sc.D.

Professor, Epidemiology and

Public Health

Department of Epidemiology and

Public Health, Institute of Human

Virology, and Greenebaum Cancer Center

University of Maryland

School of Medicine

Chernor Bah, M.A.

Youth Engagement Officer,

A World at School

Chair, Youth Advocacy Group, Global

Education First Initiative

Oretha Bestman-Yates

President

Staten Island Liberian Community

Association

Luciana Borio, M.D.

Assistant Commissioner for

Counterterrorism Policy

Director, Office of Counterterrorism

and Emerging Threats

U.S. Food and Drug Administration

Anthony S. Fauci, M.D.

Director, National Institute of Allergy

and Infectious Diseases

National Institutes of Health
William Foege, M.D., M.P.H.

Senior Fellow, Health Policy,

Carter Center

Senior Fellow, Global Health Program,

Gates Foundation

Emeritus Presidential Distinguished

Professor of International Health

Emory University

Helene D. Gayle, M.D., M.P.H.

President and CEO

CARE USA

Lawrence O. Gostin, J.D., LL.D. (Hon.)

Founding Linda D. \& Timothy J. O’Neill

Professor of Global Health Law

Faculty Director, O'Neill Institute for

National \& Global Health Law

Director, World Health Organization

Collaborating Center on Public Health

Law \& Human Rights

University Professor

Georgetown Law

Patricia C. Henwood, M.D.

Director of Global Health Initiatives

Department of Emergency Medicine

Assistant Professor,

Perelman School of Medicine

University of Pennsylvania

Diana E. Hess, Ph.D.

Professor of Curriculum and Instruction

University of Wisconsin-Madison

Senior Vice President

Spencer Foundation 
Peter Hotez, M.D., Ph.D.

Dean, National School of

Tropical Medicine

Professor, Departments of Pediatrics and

Molecular Virology \& Microbiology

Baylor College of Medicine

Endowed Chair of Tropical Pediatrics,

Texas Children's Hospital

President, Sabin Vaccine Institute

Kate Hurley, R.N., M.B.A., M.S.N.

Clinical Nurse Manager,

Intensive Care Unit

Providence St. Patrick Hospital

Unni Karunakara, M.B., B.S., Dr.PH

Senior Fellow, Jackson Institute

for Global Affairs

Yale University

Assistant Clinical Professor,

Mailman School of Public Health

Columbia University

Adjunct Visiting Professor,

Kasturba Medical College

Manipal University

Nancy Kass, Sc.D.

Phoebe R. Berman Professor of

Bioethics and Public Health

Department of Health Policy

and Management

Johns Hopkins Bloomberg School

of Public Health

Director for Public Health

Berman Institute of Bioethics
Lisa Lehmann, M.D., Ph.D., M.Sc.

Director, Center for Bioethics

Brigham and Women's Hospital

Associate Professor of Medicine

and Medical Ethics

Harvard Medical School

Associate Professor of Health Policy and

Management

Harvard School of Public Health

Daniel Levin, Ph.D.

Associate Professor

Department of Political Science

University of Utah

Howard Markel, M.D., Ph.D.

George E. Wantz Distinguished Professor of the History of Medicine

Founding Director,

Center for the History of Medicine

Professor of Pediatrics and Communicable

Diseases, Professor of Psychiatry, Professor of Health Policy and Management, Professor of History, Professor of English Literature and Language

University of Michigan

Dorothy E. Roberts, J.D.

George A. Weiss University

Professor of Law \& Sociology

Raymond Pace and Sadie Tanner Mossell

Alexander Professor of Civil Rights

Director, Program on Race,

Science, and Society

University of Pennsylvania

Seema Yasmin, M.D.

Professor of Public Health

University of Texas at Dallas

Staff Writer

Dallas Morning News 

Presidential Commission for the Study of Bioethical Issues 1425 New York Avenue NW, Suite C-100

Washington, D.C. 20005

(202) 233-3960

http://www.bioethics.gov 